
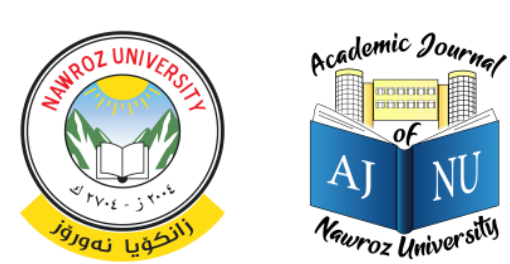

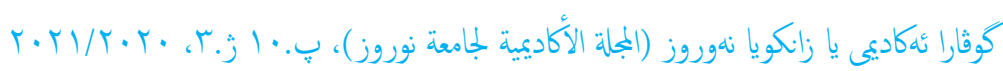

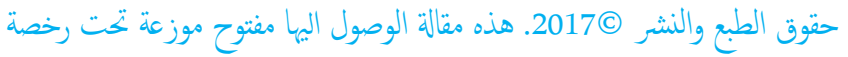

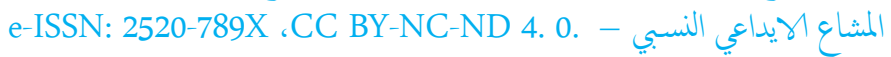
https://doi.org/10.25007/ajnu.v10n3a1065

\title{
الممكنات المتاحة لتطبيق تجربة الصناديق السيادية في اقليم كوردستان ودورها في دع الاستدامة المالية فيه
}

\author{
أ.م. د. حهند عزيز محم، قسم الاقتصاد، جامعة نوروز ، أقليم كوردستان العراق \\ ק.م بروين مصطفى حاجي، قسم الاقتصاد، جامعة نوروز، أقليم كوردستان العراق
}

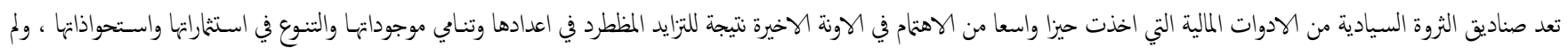

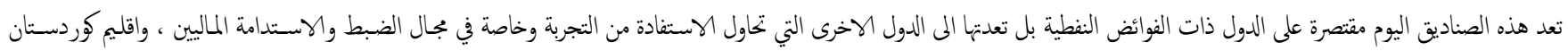

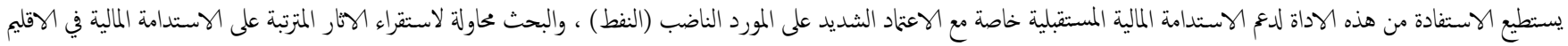

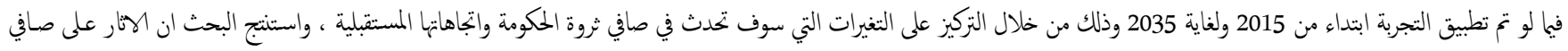
الثروة ومن ثم الاستدامة المالية سوف تكون ايجابية مع افتراض تخصيص الاقليم ل10\% من ايراداته النفطية لتمويل الصندوق السيادي فيه .

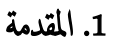

المتاحة فيه ومدى القدرة على التخلي عن جزء من هذه الموارد لدع فرصة الاجيال القادمة والتنمية المستقبلية من خلال تحويل الثروة المالية المتاحة حاليا والتي ترتبط بشكل كير بالمورد الناضب (النفط) الى اصول مالية مستقبلية يمكن الاعتماد عليها في الاجل الطويل لدعز وضع مالي مستدام في اقليم كوردستان لذلك فان البحث سيتدرج من دراسة وتحليل ما متاح من موارد مالية الى اقتراح هيكل لصندوق سيادي يدع الحفاظ عليها واستمرار تدفقها ومن ثم بيان الناثيرات المتوقعة على المؤشرات المالية المعبرة والمرتبطة بموضوع الاستدامة المالية وخصوصا

$$
\begin{aligned}
& \text { صافي ثروة الحكومة } \\
& 1.1 \text { اهمية البحث }
\end{aligned}
$$

تاتي اهية البحث من الدور الذي اصبحت تلعبه الصناديق السيادية في الاقتصادات المعاصرة سواء ذات الهمتدادات الريعية او ذات الفوائض في موازين المدفوعات او حتى الدول الساعية لدعز الاستدامة المالية لديها من خلال التوظيف السليم لبعض اموال المؤسسات والهيئات التي تتوافر لديها وفرة مالية كصناديق التقاعد والصمان الامر الذي يدعو الى ضرورة استفادة اقليم كوردستان من التجارب الدولية المختلفة في هذا المجال وخاصة تلك التجارب المتعلقة بخلق اطر مستدامة للانتفاع من الثروات بغض النظر عن كون الدولة دائنة او مدينة . لذلك فالبحث يقدم رؤية لنتمة الثروة في اطار تنبؤي وهو ما يجب ان تسعى اليه اي دولة او اقليم في العالم لتامين وضع مالي مستدام وبما يؤمن جزاء من الموارد

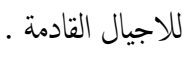

يعد ظهور الرأسمالية المالية ايذانا لتطورات عديدة شهدها المجال المالي ومن بين أهم هذه التطورات هو ظهور اداة فعالة تتمثل بالصناديق السيادية والتي عملت على تحقيق نوع من الاستقرار الملالي للدول التي تبنها ناشئ عن استثمر الفوائض المالية الناتجة سواء من عائدات تصدير الموارد الاولية كالنفط في دول الخليج مثلا أو فوائض الموازين التجارية كما حدث في دول جنوب شرق اسيا كما كان لهذه الصناديق دور ميز في المفارقة المالية العالمية المتمثلة بانتقال روؤس الاموال من الدول النامية المى الدول المتقدمة . واختلف الهدف من انشاء هذه الصناديق من بلد المى اخر ، فالبعض كان بهدف الى تحويل الثروة النفية الناضبة الى ثروة مالية مستدامة ، والبعض الاخر كان هدفه هو ضان حصة الاجيال القادمة من هذه الثروة الناضبة ، في حين حاول جزء منها ايجاد نوع من الاستقرار المالي تحسبا للصدمات ، ولم تعد هذه الصناديق اليوم تمثل حالة يمكن التخلي عنها مع غياب مسبباتها بل اصبحت اداة ضرورية لمواحمة التقلبات وحالة اللايقين في البيئة الاقتصادية العالمية وفي الآونة الاخيرة تطورت هذه الصناديق بشكل كير جدا بجيث اصبح عددها حاليا يربو على 100 صندوق رئيسي . والبحث هو محاولة لاستقراء الامكانات المتاحة لاقامة صندوق سيادي في اقليم كوردستان في ظل الواقع الملالي الحالي واتجاهاته المستقبلية اذ لابد هنا من تحديد المديات التي وصلت اليها المؤشرات الكلية والمالية الاساسية والانلاق منها لاقتراح صندوق سيادي في الاقليم ياخذ بنظر الاعتبار الموارد والممكنات المالية 


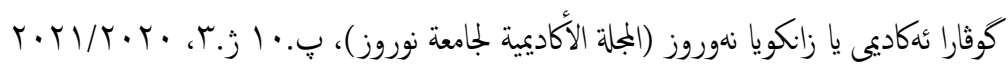

2. المبحث الاول: تحليل الواقع الاقتصادي والملالي لإقليم كوردتان

1.2 تحليل الواقع الاقتصادي لاقليم كوردستان

1.1.2 نبذة مختصرة عن اقتصاد الامليم

تبلغ مساحة اقليم كوردستان العراق (45299.83) كَّ2 ويقع بين خطي عرض (37.22-33.07) شمالا ، وادارياً يتضمن اربع محافظات رئسية هي اربيل

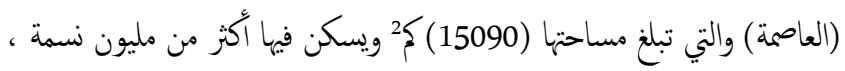

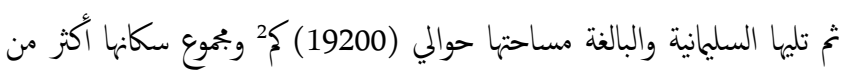
مليون ونصف نسمة ومحافظة دهوك وتبلغ مساحتها حوالي (11009.83) كم2 وعدد سكانها أكثر من (900 ألف نسمة) (اغا،4008) اضافة الى محافظة

حلبجة .

ان اقتصاد الاقليم ككيان مستقل يعد حديث المنشأ اذ كان جزء من اقتصاد العراق ولكن بعد حدوث الاتنفاضة في اذار عام 1991 حصل على نوع من الاستقلال من المركز ، ومر اقتصاد الاقليم بثلاثة مراحل ، المرحلة الاولى تمتد من (1991-2003) والمرحلة الثانية تمتد من ( 2003 -2013) والمرحلة الثالثة من 2013 الى حد يومنا هذا ، فني المرحلة الولى كان الوضع الاقتصادي صعب جدا وذلك بسبب الحصار الدولي المفروض على العراق من ناحية وحصار النظام على الاقليم من ناحية اخرى ، واعتماد الاقليم في هذه المرحلة على قدرات مالية متواضعة ناتجة من بعض الايرادات الكمركية من المنافذ الحدودية وخصوصا منفذ ابراهيم الخليل الذي كان ميثل المنفذ الثالث لحكومة المركز مع العالم الخارجي في تلك الفترة ، وساهمت هذه الموارد على الرغز من ضالتها بتمويل نخو (83\%) من الموازنة العامة للاقليم (كولدران،141،1999) اذكانت تقدر بنحو (5001500 مليون دولار) سنويا (الدوسكي ،16،2003) ، كما كان الاقليم يخصل على بعض الايرادات الضريبة والمساعدات الدولية ، وبهذه القدرات المتواضعة قطع الاقليم اشواطاً سبق بها باقي اجزاء العراق نتيجة للانتاح على العالم

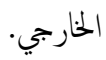

وفي المرحلة الثانية وبعد سقوط النظام البعثي شهد الوضع الاقتصادي تحسنأ كيراً نتيجة حصول الاقليم على حصته والبالغة (17\%) من ايرادات الموازنة العامة للمركز، اذ ساهت تلك الايرادات التي تزاوحت بين (8-13 مليار دولار امريكي) سنوياً للاعوام (2005-2011) في دع موازنات الاقليم والتنمية الاقتصادية فيه وخاصة بناء البنى الارتكازية ، وبالرغ من أن حكومة الاقليم قد
2.1 مشكلة البحث

تدور مشكلة البحث حول تاثيرات ريعية الاقتصاد على الاجيال الحاضرة والقادمة وعلى امكانية العمل الجاد على ايجاد البدائل المثلى للتقليل من ذلك من خلال التعمق في مناقشة الامكانات المتاحة للاستفادة من تجربة انشاء صندوق ثروة سيادي يسعى لتحقيق هدف تحويل الثروة النفطية الى ثروة مالية من خلال الثاثير على التجاه مؤشر صافي ثروة الحكومة في الاجل طويل والذي يعد مؤشر معم تركن اليه الكثير من الدراسات الحديثة للميز بين مستويات الاستدامة في الدول الريعية والتي يعد العراق واقليم كوردستان واحدة منها .

3.1 فرضية البحث

ينطلق البحث من فرضية مفادها ان اقتطاع وتخويل جزء من ايرادات المورد الناضب (النفط) في اقليم كوردستان الى صندوق ثروة سيادي يتوق ان يسامز في دع اتجاه متزايد لمؤشر صافي ثروة الحكومة ما يعني تحقق الاستدامة المالية .

4.1 اهداف البحث

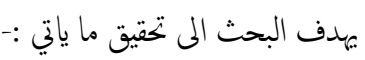
- تحليل واقع الومكنات المادية والمالية المتاحة في اقليم كوردستان · - بناء نموذج لهيكل صندوق ثروة سيادي مقترح في اقليم كوردستان وبيان تاثيره على صافي ثروة الحكومة .

5.1

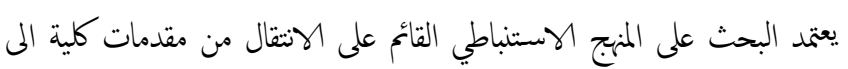
نتائج جزئة مع الوعتمد على الاساليب الكمية في التحليل والقياس .

6.1 هيكل البحث

يحاول البحث الاستدلال على موضوعه من خلال تناول المباحث الاتية :- - المبحث الثاني : شكل وهيكل الصندوق السيادي المقتزح في اقليم كوردستان - المبحث الثالث : محاكة الاثر المستقلبي لصندوق كوردستان السيادي على المؤشرات المالية فيه . - الم

وسيحاول البحث التوصل الى بموعة من الاستناجات والتوصيات التي

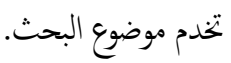




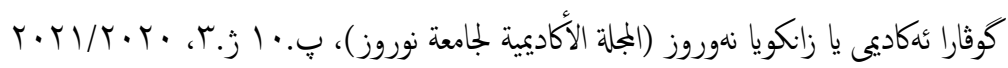

(1 ) ، وبالانتقال الى متوسط نصيب الفرد من GDP نلاحظ انه ارتغع من (524,426 دينار/سنة) عام 2004 الى (4,754,942 دينار/سنة) عام 2008 (الدوسكي, 2013, 64) والى نخو (6560,000 دينار /سنة) لعام 2014، ومن الواضح هنا دور النمو في اسعار النفط والايرادت النفطية والتي انكست على حصة ايرادات الاقليم من المركز في هذه الطفرة الكبيرة يساندها في ذلك التطور الكبير الذي حصل في البنية الاساسية ومشاريع البنى الارنكازية التي حضيت بالجانب الاكبر من الاستثمارات وهو اجراء سليم في ظل ماكانت تعاني منه هذه المشاريع في ظل العقوبات الدولية والحصار الذي فرضته المكومة السابقة على الهليم جدول 1. الناج الملمي الاجلي في كردستان بالاسعار الجارية للمدة (2008-2015) (ترليون دينار عراقي)

\begin{tabular}{llllllllll}
\hline \hline 2015 & 2014 & 2013 & 2012 & 2011 & 2010 & 2009 & 2008 & السنوات \\
\hline 34.7 & 44.5 & 46.4 & 42.3 & 35.9 & 29.2 & 23.7 & 24.7 & GDP \\
\hline-21.9 & -4.2 & 9.7 & 17.6 & 22.8 & 23.4 & -10.6 & 21.7 & الجاري
\end{tabular}

المصدر : من عمل الباحثة بالاعتماد على البطيط

1. سنة 2008 من حكومة اقليم كوردستان ، وزارة التخطيط ، خطة التنمية الاستراتيجية للسنوات 2016-2012 ، اربيل ، اذار 2011 .

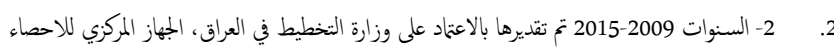
وتكنلوجيا المعلومات، الجماميع الاحصائية لسنوات مختلفة.

\subsection{2 القطاع النفطي في اقليم كوردستان العراق}

منذ الاحتلال البريطاني للعراق في عام (1918-1921) والملكية والثورات الداخلية وسقوط الملكية وقيام الجمهورية في عام 1958 كان اقتصاد العراق اقتصاداً ريعياً يعتمد بشكل كير على النفط الذي تم انتاجه في العشرينات القرن المنصرم ، فني عام 1927 قامت بريطانيا باستخراج النفط من منطقة بابا كرك القريبة من نـ

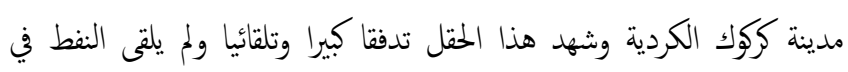
كوردستان اي اهتمام الم بعد عام 1991 حيث بدات الاستكشافات تتوالى نه وتشير الى ان الاقليم يمنلك احتياطي نفطي كير يفوق 45 مليار برميل فضلا عن حقول النفط في مدينة كروك التي تظم احتياطي يقدر ب(10 مليار برميل)

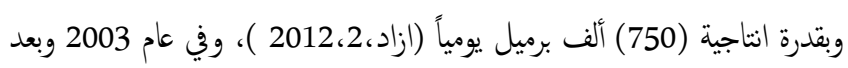
سقوط النظام بدأت الاستكشافات من قبل الشركات العالمية للمدن الكوردية اذ لوحظ ولأول مرة أهمية هذا القطاع الحيوي في الاقليم وما تملكه من
استفادت من ارتباطها بحكومة المركز وحصولها على حصتها (17\%) والتي ادى الى تحسن وضعها الاقتصادي الا أن هذا الارتباط ادى الى تأثر أغلب السياسات الاقتصادية فيه وبشكل خاص السياسة النقدية باجراءات المركز والتي كانت مرتبطة بالوضع السياسي غير المستقر فيه (مظهر،4،2008).

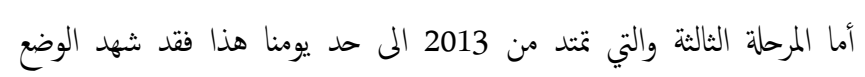
الاقتصادي فيها تراجع وعدم استقرار بسبب الخلافات مع حكومة المركز من جهة وبسبب تكاليف الحرب على الارهاب التي جاءت مترافقة مع الهبوط الحاد في اسعار النفط العالمية الامر الذي ادى المى تراجع ملحوظ في معظم المؤشرات الاقتصادية في الاقليم ادخل الاقتصاد في حالة من الرود .

\subsection{2 الناجت الملي الاجالي في الاقليم}

يعد هذا المؤشر من اهم المؤشرات الاقتصادية لانه تعبير دقيق عن بمحل النشاط الاقتصادي في اي بلد وعن مدى مساهمة القطاعات الاقتصادية في تكوين هذا الناجت ، وهذا المؤشر في كوردستان يعاني من نغس المشاكل التي تؤثر في اي اقتصاد ريعي والمتمثلة بهيمنة قطاع انناج المواد الوولية (القطاع الهيدروكوربوني) ومساهمته الكبيرة في هذا الناتج وهذا ما ادى لاحادية الجانب في الاقتصاد ، وتساهم الايرادات النفطية بنحو 62\% من GDP في الاقليم وهو مؤشر مرتغع يدل على ضعف مساهمة القطاهات الاخرى وخاصة القطاعات الانتاجية مثل

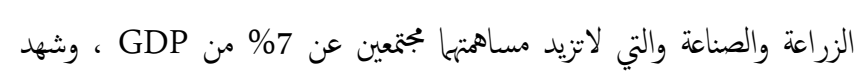
هذا المؤشر نموا كيرا للمدة 2003-2015 جاء لعدة اسباب من ضمنها استمرارتدفق حصة الاقليم من الموازنة العراقية بشكل شبه منتظم ، والانتاح الاقتصادي على العالم الخارجي الذي ادى المى تدفق الاستثارات الاجنبية وعودة الكثير من المستثمين المحليين خاصة مع الاستقرار الامني الذي شهده الاقليم طوال المدة المذكرة ، وعلى هذا الاساس انتقل GDP في الاقليم وبالاسعار الجارية من (2419.6 مليار دينار) في عام 2004 الى نخو (24725.7 مليار دينار) في عام 2008 حيث بلغ معدل التغير للمدة (2004-2008) نخو (1022\%) وبمعدل نمو مركب قدره (68.9\%) للمدة للمدة ذاتها (نبيل و الجوارين, 2012) ، في حين سبل هذا الناتج اعلى قيمة له في عام 2013 اذ بلغ نحو (46.4 تزليون ID) ليعاود بعدها الوخفاض للعامين الاخيرين ، اما فيا يتعلق بمعدل النمو فقد وصل الى اعلى قيمة له عام 2010 اذ بلغ نحو (23\%) وليعاود الانخفاض والاتجاه السالب للسنوات الاخيرة وكما موضح في الجدول رقخ 


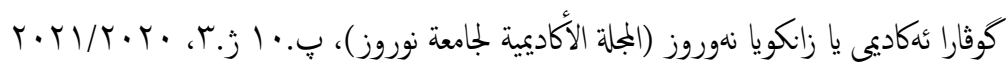

\section{2 الموازنة العامة لاقليم كوردستان العراق}

يككن تعريف الموازنة العامة على أنها وثيقة أساسية لدراسة المالية العامة لأي دولة ،والتي يتضح من خلالها مصادر الايرادات العامة لها ، واتجاهات الانفاق العام والذي يحدد كيفية توزيع موارد الدولة المالية على مختلف القطاعات الاقتصادية والذي من خلاله تتبلور فلسفة النظام فيا يتعلق بالاليات المتبعة لادارة وتوجيه

النشاط الاقتصادي (شهاب،261،1999)

وتعد الموازنة العامة اداة همة ولها دور كبير وفعال في تمكين الادارة الاقتصادية من تخطيط ورقابة النشاطات الاقتصادية ومدى تحقق الأهداف لانها تعطي صورة بالموقف المالي للدولة وفيا اذا كان هناك جزز أو فائض لتاك السنة ، وهي ايظا تعكس مضمون فلسفة السياسات المالية الممتمدة وتوجهاتها الاقتصادية وخياراتها الاجتماعية ونطاق تأثيراتها في بجمل النشاطات الاقتصادية وصولاً لحالة من الاستقرار الاقتصادي المقاوم للضغوط التخمية والانكماشية وبما يضمن استدامة التنمية وتحقيق العدالة في التوزيع (الخطة الاستراتيجية لاقليم كردستان

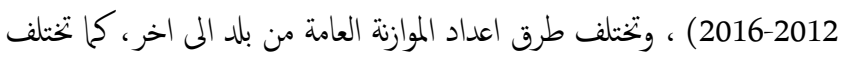
الجهات التي تقوم باعدادها تبعاً للنظام السياسي والاقتصادي المتبع (الواحد،1996، ص159). وفي اقليم كوردستان بدات الحكومة ومنذ التسعينات من القرن المنصرم باعداد مثل هذه الموازنات والجدول (2) ييين الايرادات والنفقات والعجز لموازنات الاقنيم للمدة (2008-2015) جدول 2. هيكل الموازنات العامة لاقليم كردستان للمدة (2008-2015) (مليون دينار عراقي)

\begin{tabular}{|c|c|c|c|}
\hline العجز & النفقات العامة & الايرادات العامة & السنوات \\
\hline-1047999 & 7628783 & 6580784 & 2008 \\
\hline-574091 & 8857263 & 8283172 & 2009 \\
\hline-835000 & 11432176 & 10597176 & 2010 \\
\hline-1564670 & 13950670 & 12386000 & 2011 \\
\hline-2044847 & 15245797 & 13200950 & 2012 \\
\hline-1684900 & 16942749 & 15257849 & 2013 \\
\hline-2600000 & 15800000 & 1320000 & 2014 \\
\hline-3100000 & 15100000 & 1200000 & 2015 \\
\hline
\end{tabular}

1- السنوات (2013-2008) موقع برلمان اقليم كوردستان ، على الموقع الككتوني www.Pereleman.org

2- السنوات 2014 ، 2015 تم تقديرها من قبل الباحث بالاعتماد على موازنات المركز للاعوام المذكورة

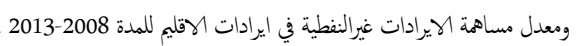

الاحتياطيات النفية ودور الرئيسي الذي سوف يلعبه هذا القطاع في مستقبل الاقليم ، واستمر العمل من قبل الشركات الى ان تم استخراج وتصدير النفط في بداية عام 2009 ومن حقول جديدة في اقليم كوردستان ، وفي عام 2010 سجل لاول مرة بقانون الموازنة العامة لحكومة المركز حجم الصادرات المطلوبة من الاقليم

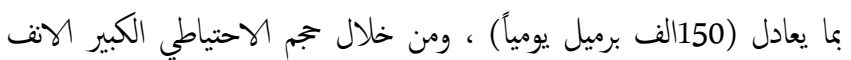

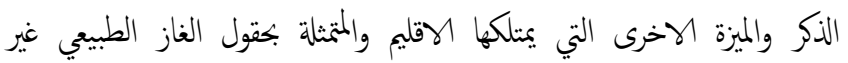
المصاحب دخل اقتصاد الاقليم مرحلة جديدة من الاستثمارات الهيدروكبونية اذ من المؤمل ان يكون انتاج الغاز وتصديره من خلال خط (نابوكو) الذي يبلغ طوله (4000) ؟ ، ويقدر حجم الاحتياطي من الغاز في الاقليم بنحو (71-100)

$$
\text { ترليون قدم مكعب (الدوسكي، مصدرسابق،صن (72). }
$$

\subsection{2 قطاع السياحة في اقليم كوردستان} من القطاعات الاخرى التي لها تأثير في دع اقتصاد الكثير من الدول قطاع لهُع السياحة الذي عندما تتوفر المقومات الاساسية له يستطيع دع النمو بشكل كير ، ويخظى اقليم كوردستان بريع الموقع نظرا لوجود المناطق السياحية والمناظر الخلابة والتي تتمتع بجو مناخي منتظم أي يكن رؤية اربعة فصول السنة فيه ، ويدع هذا

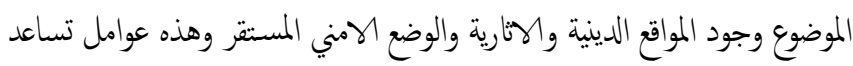
على جذب السياحة بشكل كير وقامت حكومة اقليم كوردستان باصدار التشريعات والانظمة واللوائُ السياحية في قانون رقٌ (39) لسنة 2004 وشكلت المؤسسة العامة للسياحة (زوزان،2011،79) ، كما نفذت الحكومة العديد من المشاريع السياحية ودعمت الخدمات الفندقية والمراكز الثقافية والتجارية وبناء المطاع و مدن الاعلب في الاماكن السياحية والمصايف وتوفير متطلبات السياحة في أغلب مصايفها ، ورغز ذلك الا ان الاقليم لم يصل الى المستوى المطلوب من استغلال هذا المورد الاظافي ولابد من بذل جهود كيرة من اجل دع مساهمته في الGDP بالمستوى الذي يضاهي الممكنات المتاحة للنجاح وهي كثيرة خاصة وان هذا القطاع له تأثير كير في حل الكثير من المشاكل الاقتصادية التي يعاني منها الاقليم في مقدمتها البطالة ، وتقليل الهجرة من الريف المى المدينة ، وتوفير عائدات اضافية الموازنة ، وتوفير العملات الاجنية ، والتعرف على مختلف الثقافات والعادات والتقاليد ، ونمو وتطور العلاقات التي تساهم في توسيع النطاق التجاري مما يساعد على التنمية الاقتصادية في البلد. 


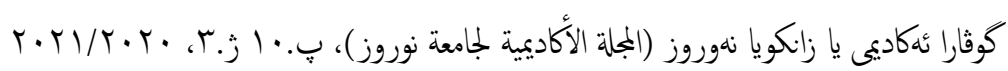

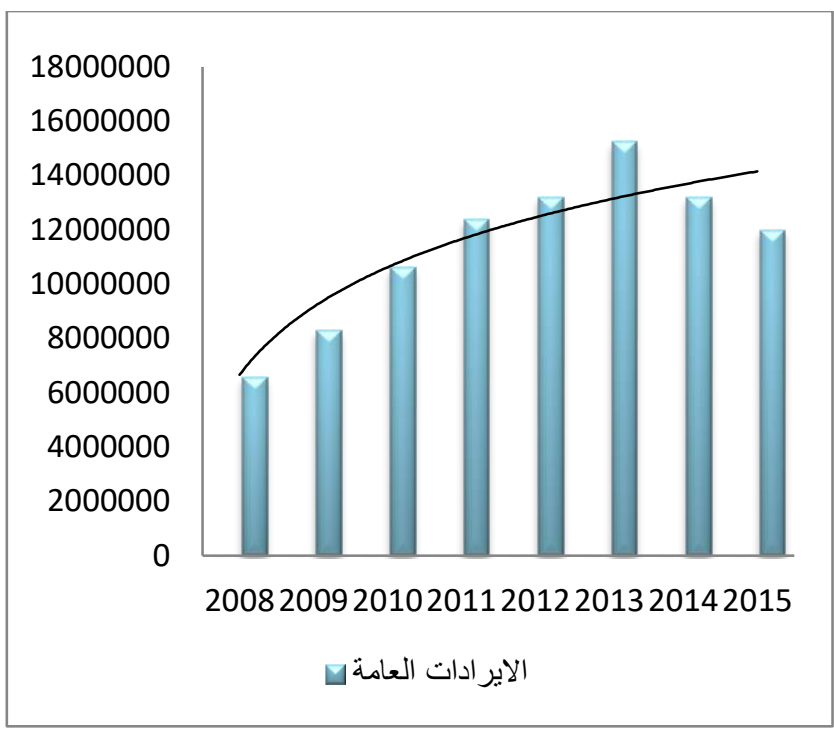

المصدر: من عمل الباحث بالاعتاد على جدول (2)

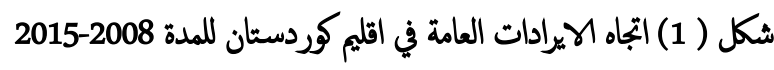

2.2.2 النفقات العامة لموازنات الاقليم للمدة (2008-2015)

تمثل النفات ركنا اساسيا من اركان الموازنة العامة ،وهي أحد ادوات السياسة المالية التي تتبعها الحكومة من أجل تحقيق أهدافها ، وتتخلف السياسة الانفاقية من دولة الى اخرى حسب طبيعة النظام الاقتصادي القائم ، فئلاً تسعى الدول المتقدمة الى تحقيق الاستقرار الاقتصادي وتخفيض معدلات البطالة ومكافحة التضخم ، بينا الدول النامية تسعى الى بناء بهاز انتاجي متطور وتوفير السلع الاستهلاكية الاساسية للسكان ، وانطلاقاً من هذا يقع على السياسة المالية ومن خلال ادواتها واجب السعي لتحقيق اهداف السياسة الاقتصادية للبلد . (العبيدي ،234، (2011)

ويلاحظ من جدول رقز ()بانه هناك زيادة مستمرة في النفقات العامة للمدة (2013-2008) اذ انتقلت من ادنى مستوى لها (7628783 مليون دينار عراقي) وذلك في عام 2008 الى اعلى معدل لها (16942749 مليون دينار عراقي) عام 2013 وبمعدل نو (222\%) ، ولكن النفقات اخذت بالتراجع للعامين الاخيرين بسبب تراجع الايرادات للاسباب الانقة الذكر لذلك اظطرت حكومة الاقليم الى لى ضغط الكثير من نفقاتها التشغيلية والاستثرارية ويلاحظ من الجدول ايظا ان اقل معدل للزيادة في الانفاق كان بين عاي 2008 و 2009 وذلك بسبب ثاثيرات الازمة المالية العالمية وتراجع الايرادات النفطية ، في حين كان اعلى معدل للزيادة في عاي 2009 و2010 وذلك بسبب تحسن اسعار النفط العالمية ، ومن الجدير بالذكر هنا ان اسباب هذا التزايد المستمر في النفقات يرجع الى الاسباب الحتيقية (المالية، الادارية، الاقتصادية، الاجتاعية، السياسية ) ، والاسباب الظاهرية

والاتي تفصيل لمكونات هذه الموازنات خلال المدة السابقة :-

1.2.2 الايرادات العامة لموازنات الهليم للمدة (2008-2015) تعتبر الايرادات العامة احدى الأدوات المهمة التي لها تأثير كير على الاوضاع الاقتصادية والاجتاعية ، ومن وظائفها تغطية النفقات العامة ، وكذلك توجيه الاستثڤرات ، وان للايرادات العامة سياسة تسمى (Revenues Policy) وتضمن هذه السياسة في فرعين اساسيين هلا السياسة الضريبية ( Taxing Policy ) ، وهي تلك السياسة التي تتبعها الحكومة عند قياهما بفرض الضرائب على الدخول والثروات ، الضرائب على السلع ، والسياسة الاقتزاضية (Loaning Policy) الضرائب المى حدها الاقصى أو عندما تكون للضريبة ردود أفعال عنيفة (مصطنى،السيد،1998،ص139) ، وهناك أنواع اخرى من الايرادات التي تحصل عليها الدولة مثل ايرادات الدومين العام والخاص ، والرسوم والغرامات ،

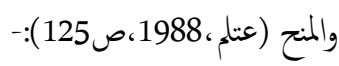
وفي اقليم كوردستان تهيمن الايرادات النفطية والمتانية بشكل حصة (17\%) من ايرادات الحكومة المركزية على بجمل الايرادات العامة فيه وهي تشكل نحو 95\% منها في حين لتساهم مصادر الايراد الاخرى ومنها الضرائب الابنسبة ضئيلة لاتتجاوز (5-10\%) في احسن الاحوال ، وذلك لجملة من الاسباب اهها الحادية الجانب في الاقتصاد وضعف مساهمة القطاعات الانتاجية في GDP ، رد ومن ملاحظة الجدول (2) نلاحظ ان الايرادات العامة شهدت تزايد مستمر للمدة ( 2008-2013) ويعود سبب هذا الارتفاع الى تناي انتاج النفط على المستوى المحلي سواء لحكومة الاقليم او حكومة المركز وكذلك الارتفاع الذي شهدته اسعار النفط العالمي وخصوصا للسنوات 2011-2013 ، وكذلك ساهم الاقتاح الاقتصادي للاقليم مع العالم الخارجي في زيادة الايرادات المحلية ، ولكن هذه الايرادات اخذت بالتراجع للعامين الاخيرين 2014 ، 2015 وذلك تحت تاثير تراجع اسعار النفط والصراع السياسي في المركز والذي افضى لسيطرة

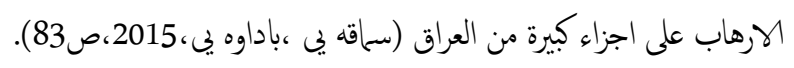
والشكل (1)يوضح اتجاه ايرادات موازنات اقليم كوردستان للمدة (2008(2015 


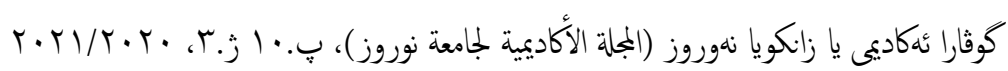

الستراتيجية التي اتبعتها الحكومة في التوسع في الانفاق على البنى التحتية ومحاولة

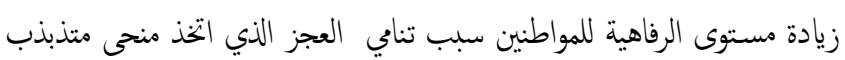
خلال المدة (2008-2015) اذ انخفض من (1047999- مليون ID) في عام 2008 المى (574091- مليون ID) في عام 2009 وييدو واضحا ان الازمة المالية العالمية لم توثثر بشكل كير على ايرادات الاقليم وذلك بسبب دع موازنة المركز من خلال الفوائض السابقة التي تراكت بسبب الفوائض المالية للسنوات السابقة وعدم استمرار الانخفاض في اسعار النفط لاكثر من شهر واحد عاودت بعدها الارتفاع ، وبعد ذلك اتخذ العزز مسارا تصاعديا حتى وصل الى (2044847مليون ID ) عام 2012 ويبدو ان التوسع في الانقاق للسنوات السابقة والمقترن بالثفؤل حول ارتفاع انتاج واسعار النفط هو الذي قاد الى التادي في الانفاق العام اذ تضاعفت اجور الموظفين في هذه المدة والتي تسيطر على اكثر من (70\% ) من النفقات التشغيلة للموازنة وعلى نحو ( 50\%) من نقات الموازنة العامة ، وتحت وطاة نمو الايرادات بسبب وصول اسعار النفط الى ارقام قياسية في عام 2013 تراجع العجز في الموازنة ليصل الى (1684900- مليون ID ) ، ثخ عاود العزز الارتفاع ليصل الى مستويات قياسية للعامين الاخيرين وذلك تحت

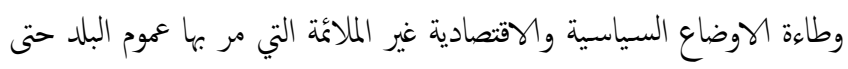
قدر العجز في موازنة الاقليم لعام 2015 بنحو (3100000- مليون ID). الشكل (3 ) يوضح اتجاه عجز الموازنة في اقليم كوردستان للاعوام (2008-

$(2015$

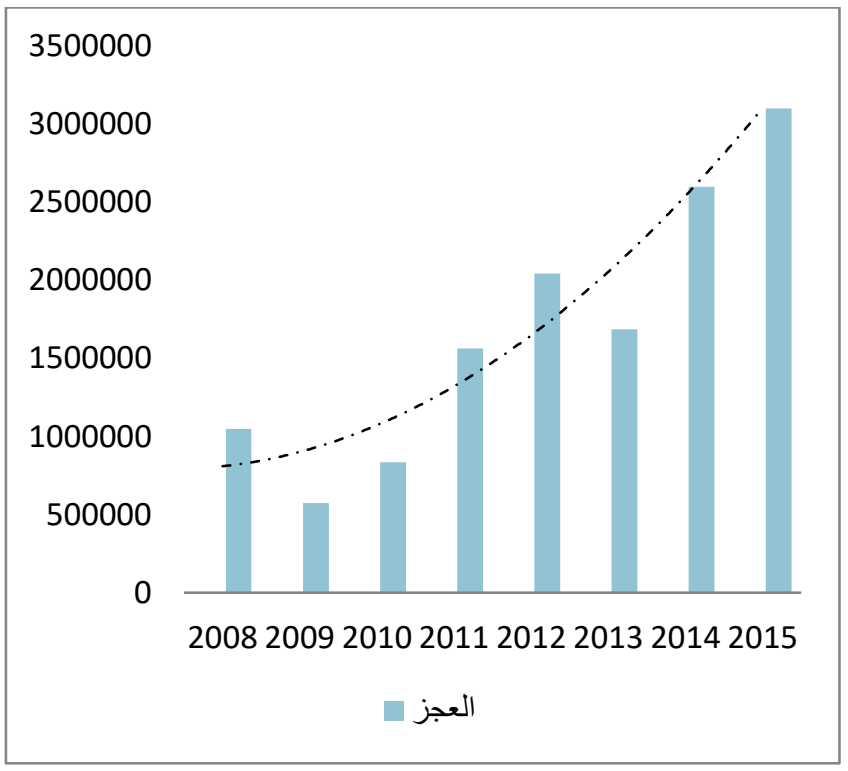

المصدر : من عمل الباحث بالاعتاد على الجدول (2)

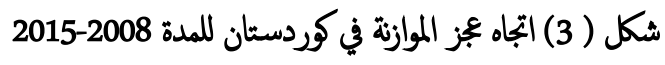

والمتثثلة ب(زيادة عدد السكان ، التضخم ، تغير التعليمات المالية ). (الحيدري،123،2014). على ان السبب الاساسي لزيادة النفقات هو توفر الايرادات المثاتية من حصة الاقليم في النفط اذ غالبا ما تتبع النفقات الايرادات في الدول الريعية والملاحظ هنا ان اغلب الزيادة جاءت من خلال تناي النفقات التشغيلية والمتثلة بالرواتب والاجور على حساب النفقات الاستثراية ويبدو ان توجه الدولة نخو التوظيف لتقليل البطالة وتعويض الجمتع عن سنوات الحرمان التي عانى منها ابان النظام السابق وذلك من خلال التوسع بتقديم الخدمات الاساسية بشكل مجاني او مدعوم هو الذي دفع بها الاتجاه خاصة مع حالة الوفرة في الموارد

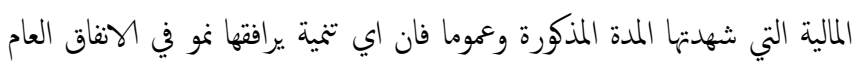
وظاهرة نمو النفقات العامة هي ظاهرة عالمية . والشكل (2 ) يوضح اتجاه النقات العامة في اقليم كوردستان للمدة (2008(2015

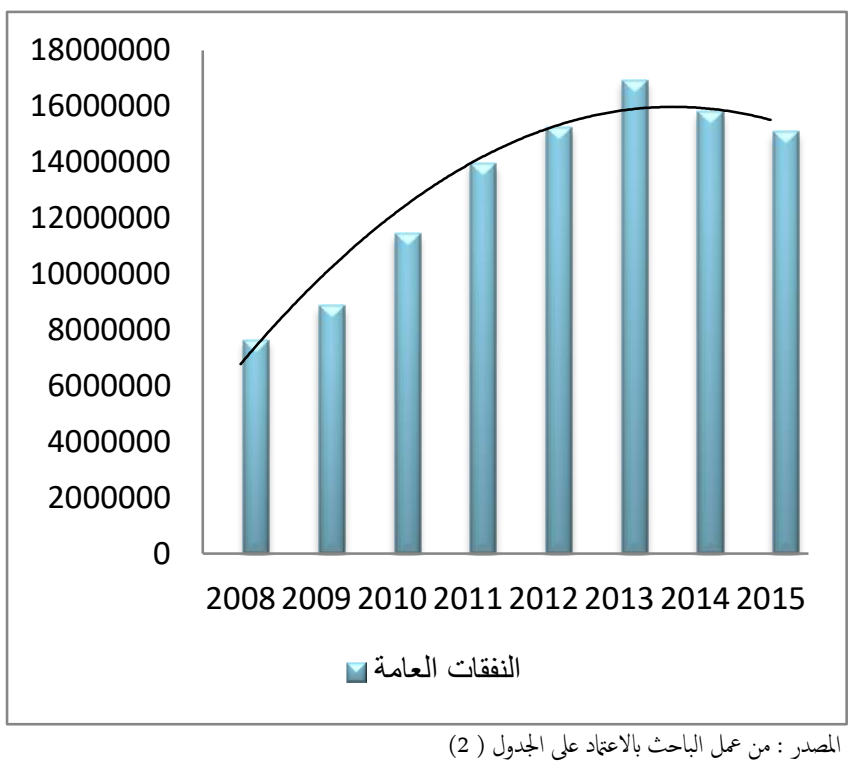

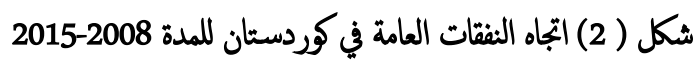

3- العجز في موازنات اقليم كوردستان للمدة (2008-2015) ينشاء العجز في الموازنة بسبب تفوق النفقات على الايرادات وهنا تكون اشارة العجز سالبة ويكن ان يكون العجزي باشارة موجبة وذلك عندما تتفوق الايرادات على النفقات وفي هذه الحالة تكون الموازنة في حالة فائض ، وفي كثير من دول العالم يتم في العصر الراهن وضع الموازنات بعجز مقصود وذلك بهدف تمويل المزيد من الانفاق الداع لنمو الدخل القوي والناتج المحلي الاجلالي ، وفي اقليم كوردستان نلاحظ ومن خلال الجدول (2) ان جميع موازنات الاقليم شهدت حالات كجز مستمرة خلال المدة (2008-2015) وييدو واضحا ان 


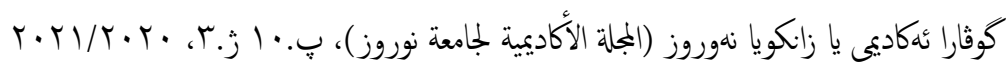

تدخل الدولة ،والصناديق السيادية هي نوع من انواع هذا التدخل .

2.3 الموارد المثاحة امام الصندوق:-

يمتلك الصندوق السيادي المتتح في اقليم كوردستان العديد من الموارد التي تضمن تقديم التمويل له ومن بين اهم تلك الموارد ما يأتي:

النفط والغاز يمتلك اقليم كوردستان خزيناً هائلاً من النفط والغاز وان اسعارها رغ التراجع الذي شهده حالياً لكنها مرشحة للزيادة وفق اسوء التقديرات المستقبلية وذلك بسبب استمرار جزء من هذه الموارد لتمويل الصندوق بنسبة معينة سواء اكانت هذه ايرادات مثأنية من البيع المباشر من قبل اقليم للنفط والغاز او من خلال ما يحصل عليه من سبة (17) من الحكومة المركزية في كلا الحالتين توجد امكانية حقيقية لتمويل الصندوق عن هذا الطريق، والحال نفسه ينطبق على موارد الاقليم من

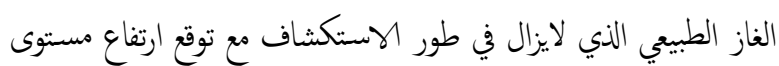
الاحتياطيات المتوفرة منه الى كميات قياسية وفق ما يشير الى ذلك اخر ترك التقديرات في هذا المجال وبإمكان الحكومة هنا وبادي ذي بدء حجز ايرادات الغاز وعزلها عن الايرادات النفطية وتوجيها نخو الصندوق سيادي يضمن الحفاظ عليها وتدويرها في استثمرات واصول نابحة .

الفوائض في ميزانيات الاقليم: بسبب ضعف الطاقة الاستيعابية للاقتصاد وعدم قدرة القطاعات الحكومية على الانفاق ما يخصص لهاضمن الموازنة يحدث في كثير من السنوات ان تتولد فوائض مالية في الحسابات الحتامية غالباً ما تدور الى الموازنات اللاحقة اذ بالإمكان استغلال مثل هذه

$$
\text { الفوائض بتحويلها الى الصندوق السيادي . }
$$

ايرادات الخصخصة : يمناك الاقليم العديد من المؤسسات الحكومية والراضي والدومين العام المملوك من قبل الدولة والذي من الممكن تحويله جزءا أو كلاً المى القطاع الخاص عن طريق البيع أو الشراكة واستغلال الاموال المترتبة من هذه العملية لتمويل الصندوق السيادي وبذلك يككن ضان عدم ضياع مثل هذه الاموال او ذهاها في شكل نقات استهلاكية

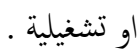

يككن أن تساهم الحكومة برأس مال تأسيسي لهذا الصندوق ثم ادراجه كفقرة في الموازنات لسنوات مختلفة وكذلك يكن تمويل الصندوق عن طريق وضع كل أموال الثقاعد والضان إليه أو من خلال اقتح برنامج تقاعدي
3. المبحث الثاني: شكل وهيكل الصندوق السيادي المقتح في اقليم كوردستان نظراً لان الصناديق السيادية لم تعد حكراً على نوع من الدول دون الاخرى بسبب تعدد الاغراض والاهداف التي تنشأ من اجلها فان خصوصية الوضع في اقليم كوردستان يتطلب نوعاً خاصاً منها يأخذ بنظر الاعتبار طبيعة الاقتصاد والممكنات المتاحة فيه واتجاهات السياسة الاقتصادية لديه وفي هذا الكار يكن اعطاء صورة مبسطة عن شكل الصندوق السيادي المقترح من خلال تناول

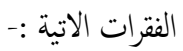

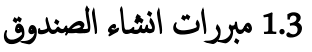

يعاني اقتصاد اقليم من اختلال هيكلي ناشئ عن احادية الجانب المتمثلة بهيمة القطاع النفطي على بقية القطاعات التي تمتاز بضعف كير في مساهمها في

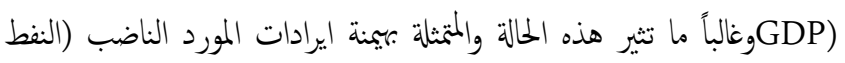
والغاز) سواء على (GDP) أو على ايرادات الموازنة تحدياً من نوع خاص يسمي بلعنة المورد والذي قدمه صندوق النقد الدولي على انه (ظاهرة معقدة تساعد فهيا وفرة ايرادات المورد الطبيعي على نشوء حالات من الكساد، والهدر، والفساد، والنزاع) وذلك من خلال اليات اقتصادية ومؤسسانية ترتبط بتداعيات الاقتصاد السياسي لذلك فان الصندوق السيادي في اقليم كوردستان يكن ان يجنب الاقليم الكثير من هذه الاثار الضارة من خلال تقليل النمو المستمر في الانفاق العام الممول بايرادات النفط (المرض الهولندي) وما يترتب عليه من ارتفاع اسعار السلع المحلية وضعف قدرة الاقتصاد التنافسية هذا من جانب ومن جانب اخر يساعد الصندوق على المساعدة في تجنب التقلب الشديد في الايرادات والمرتبط بتقلب اسعار النفط العالمية وما يؤدي اليه من زيادة حدة الدورات النجارية ودفع الاقتصاد نخو مزيد من الديون وفقدان الاستدامة المالية ،كما ان الصندوق يكنن ان يساهم على الحفاظ على المورد الناضب من خلال استبداله بمورد مالي يخدم مصاح الاجيال الحالية والقادمة أو حتى استبداله بأصول حقيقية وانتاجية وبنى

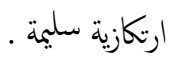
كذلك يكن لمثل هذا الصندوق ان يجعل الحكومة تتخلى عن كثير من اهتمامتها بوظائف اعادة التوزيع (مثل أنواع الدع ،والتضخم البيروقراطي للمؤسسات الحكومية)التي يككن ان تكون غير فعلة كما هو الحال في الوظائف المتعلقة بالإشراف والتنظيم والضرائب والادارة الاقتصادية الفعالة وقد اثبتت التجارب العملية في العالم ان التدخل المدروس والفعال يمكن ان يجقق تطور اقتصادي رغز 


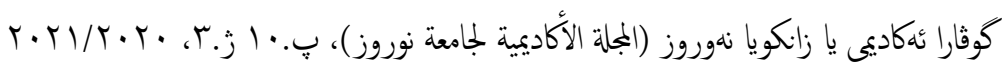

مالية يعمل على تنشيطها بشكل كير من خلال زيادة جحم التداول وعدد شركات المسجلة ز كذلك احداث نوع من التوازن القطاعي داخل السوق بالتركيز على القطاعات الانتاجية و هذا ما تم مشاهدته في الكثير من توفير الدئ للحكومة و موازناتها في المنح الطارئة والحمتلة و التي لا تملك تويلا لها ودع هياكل التقاعد للحكومة فضلا عن التأمين الذاتي ضد

$$
\text { التقلبات في أسعار النفط. }
$$

تعظيم العائد لموارد الحكومة باتخاذ مسار كلفة الفرصة البدية كأساس

لضغط الانفاق و دع الادخار و زيادة المكاسب من عملاتها الأجنية.

\section{3 الهيكل التنظيمي المتتح للصندوق السيادي في كوردستان}

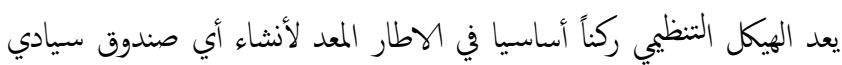
لأنه يمثل تصورأ حول المسؤوليات و الصلاحيات و آليات ادارة موجودات

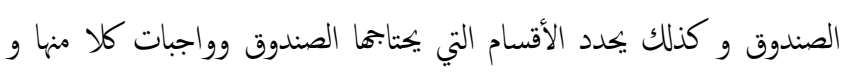
الشكل (4) يوضح الهيكل التنظيم المقترح لصندوق كوردستان السيادي و الني تلاحظ من خلاله ما يأتي:-
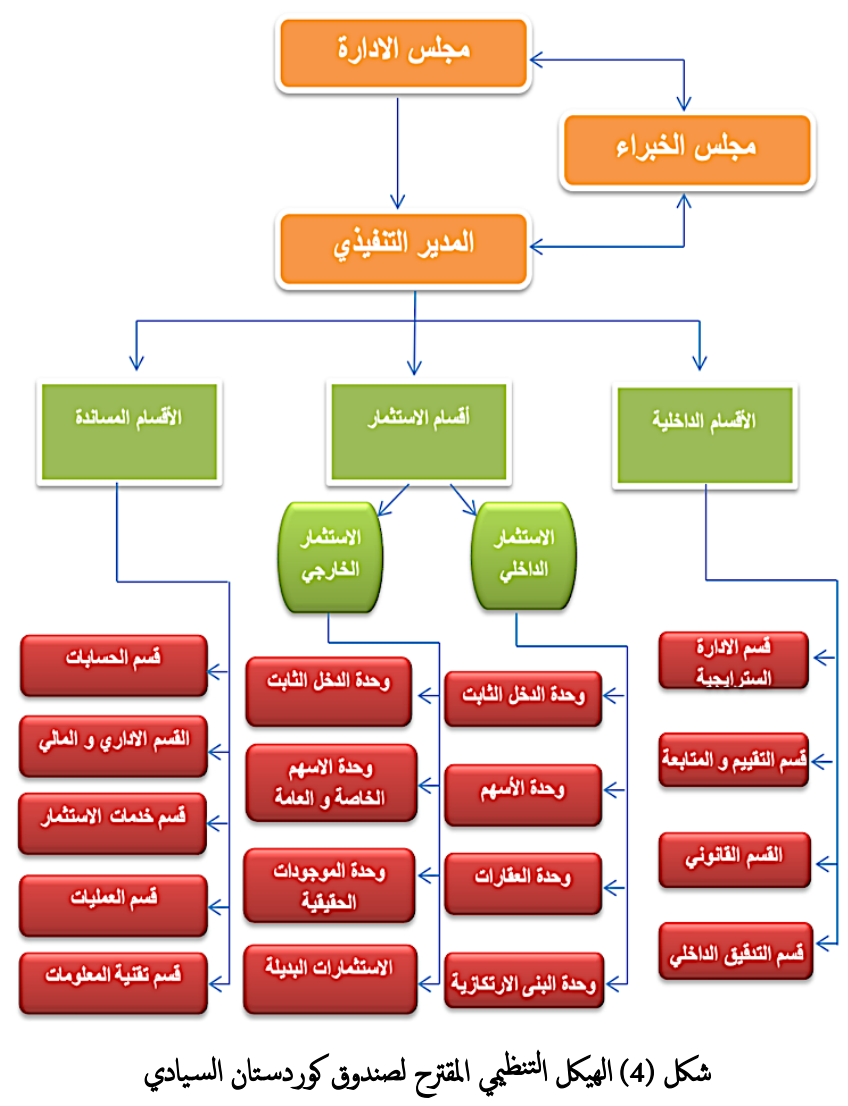

المصدر : من اعداد الباحثة بالاعتماد على:-

Sameer Jain integrating hedge fund strategies in sovereign wealth portfolios, Citi capital Advisors, 2009, p: 3
مستقبلي لأصحاب المهن الحرة و القطاع الخاص مقابل الإيفاء بالالتزامات مالية معينة تقوم بها أفراد المتمولون و لفترة زمنية محددة قبل استحقاق الحصول على مثل هذا الهتياز (تقاعدي)

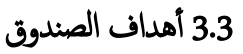

بعد تحديد مبررات انشاء الصندوق و مصادر التي من الممكن أن يعتمد عليها أصبح بالإمكان الآن اعطاء صورة لأهم الأهداف التي سوف يسعى الصندوق الى تحقيقها و التي من الواضح انها لن تبتعد كثيراً عن التوبحات الهامة لمجمل الصناديق السيادية الاقليمة و العالمية مع الأخذ بنظر الاعتبار خصوصية اقتصاد إقليم كوردستان وطبيعة التحديات التي يواجهما ويكن إجال أهم الأهداف التي سوف يسعى اليها هذا الصندوق و كما يأتي: تحتيق المزيد من الاستقرار في اقتصاد الاقليم من خلال العمل على برجة الايرادات المالية المتقلبة والتي يصعب التنبؤ بها و العمل على رفع مستوى الشفافية في إدارة هذه الايرادات وفي السياسة المالية برمتها و بالشكل الذي يؤدي الى ظهور أثر هذه الإيرادات على التنمية الاقتصادية. رفع معدل القيمة المضافة لاقتصاد الإقليم والتخلص من احادية الجانب و احادية المورد وذلك من خلال العائد المتحقق على خدمة الاستثارات الاخلية حزمة الاستثمارات الاخلية والخارجية التي سوف يعمل عليها

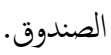

الادخار للأجيال المستقبلية و ضبط الانفاق العام و عدم تبديد الثروة والعمل على تحويل مردودات المورد الناضب الى مفظة من الموجودات الاكثر تنوعا والاقل مخاطرة تمكن من امكانية الاستفادة منها للضبط المالي الحلي و المستقبلي وذلك من خلال تحتيق الاستخدام الأمثل لثروة النفط والغاز عن طريق استثارها في مشاريع ذات الدخل الثابت و مستقر و الأكثر ديموة وعدم التعامل معها على أنها دخل دائم إذ لابد اللقائمين على ولى السياسة المالية في الاقليم من الاستعداد لموابجة تحدي نضوب النفط. تحفيز المستمر المحلي وجذب المستثمر الاجنبي و تنشيط سوق الأوراق المالية إذ و فيا يتعلق بالاستثمار المحلي و الأجنبي فإن ارتفاع مستوى

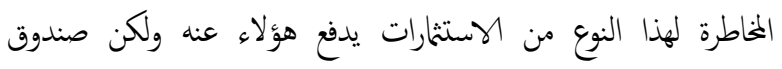
السيادي بإمكانه تحمل جزء من هذه الخخاطرة عن طريق مشاريع الشراكة أما فيا يتعلق بسوق الاوراق المالية فإن دخول الصندوق كستثمر ذو ملاء 


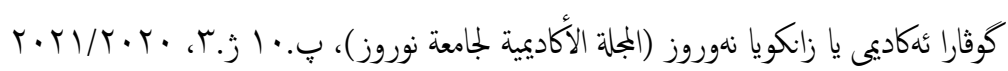

الاقسام الساندة وهي أيضاً ترتبط بالمدير التنفيذي وتعمل في ضوء تعليماته وتقدم التقارير اليومية له كما انها ذات اهمية بالغة لدع الاقسام الباقية وخاصة قسم الاستثمار الذي يعد محور الصندوق فعلى سبيل المثال يعد قسم تقنية المعلومات الذي يعد من الاقسام الساندة ذو اهمية فائقة لما له من دور في دع قسم الاستثار بكافة المعلومات المتعلقة بسير الاسواق المالية والعالمية وتبويب وتحليل البيانات التي تعد ذات اهية قصوى لقسم الاستثمار في مجال عمله وهكذا الحال بالنسبة لقسم خدمات الاستثار والاقسام الاخرى التي لا تقل اهمية في هذا المجال . اقسام الاتتثار تقوم هذه الاقسام بأهم النشاط للصندوق السيادي والمتمثل بالعمل على الادارة الاستثار لموجودات الصندوق ذلك من خلال بناء و ادارات المحافظ الاستثمرية ضمن معايير تخصيص الاصول المعتمدة و هذه الاقسام لابد أن تتمع بقدر مناسب من الحدية في ادارة و توجيه استثغراتها و في ضوء استراتيجية عمل الصندوق ويتم السيطرة على هذه الاقسام. و تخضع لسيطرة رؤساء محتفين يتبعون للمدير التنفيذي للصندوق ولابد من العمل على تجزئة قسم الاستثمار الم فرعين الأول للاستثار الخارجي و الثاني للاستثمار الداخلي, ولابد من أن تخضع كلا الفرين لمبادئ توجيهية صارمة ومراقبة دقيقة من أجل ضمان إدارة مخاطر قوية و خصوصا ما يتعلق بفع الاستثار الخارجي الذي بمارس الاستثمار في الأسهم العالمية من خلال تنسيق مع مراكز الاستثار في هذا المجال من أجل التعرف على فرص الاستثمار العالمية المتاح و ذلك بعثابعة الانشطة التجارية و المالية على أساس يوي و تقديم تقارير حولها و هذا يكون من خلال وحدة الأسهم الخاصة والعامة والتي تقوم بتوزيع استثاراتها بين النوعين(الأسهم الخاصة والعامة)من أجل رفع معدلات العائد و الربحية وخاصة في مجال الاستثمار في الشركات الخاصة ولابد من أن تعمل هذه الوحدة على تنويع استثمراتها من النواحي الجغرافية والقطاعية و الزمنية. ومن بين الوحدات المهمة الأخرى إيلاهُا اهتماماً خاصاً هي وحدة الدخل الثابت و التي غالباً ما تركز على الاستثغرات القصيرة الأجل عبر إدارة مجموعة واسعة من الأوراق المالية ذات الدخل الثابت مثل أذونات الخزانة و السندات لسنة واحدة والصكوك العالمية الحكومية،ويجب ان يكون أهداف هذه الوحدة تلبية احتياجات الصندوق الى السيولة والحصول على
إن الواجبات المسؤوليات داخل الصندوق تأخذ شكلاً هرمياً مبتداً من الرأس المتثثل برئيس مجلس ادارة الصندوق و متتهي بالأقسام و الوحدات الاستثارية والساندة و من أجل إضفاء مزيداً من الدقة و الشفافية في عمل الصندوق يفضل أن يكون رئس مجلس الادارة من أصحاب المناصب العالية كأن يكون رئس الوزراء أو أحد الوزراء الاساسيين في الدولة مثل وزير المالية أو وزير الموارد ولابد من اعطائه صلاحية كاملة لتوجيه الصندوق في ضوء الاهداف و الاغراض التي انشأت من اجلها و اتخاذ ما يراه مناسبا من استراتيجيات في هذا الغرض أما أعضاء مجلس الحدارة فلابد أن يكونوا من ذوي الاختصاص كان يكونوا مثثلين عن الوزارات و الادارة الاقتصادية الاساسية في الاقليم مثل مثل عن قطاع المصرفي ومثثل عن الوزارة الماليةو وزارة الموارد. مع إمكانة تعزيز هم لعدد من أعضاء اللجنة الاقتصادية في مجلس النواب من أجل ضانة اطلاع السلطة التثريع على عمل هذا الصندوق وسيره في الاهداف المعلنة لم وبما يضمن

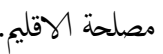
المدير التنفيذي للصندوق هو الحلقة الاهم في هذا المجال لأنه المسؤول المباشر عن المتابعة اليومية لعمل الصندوق وتوجيه موجوداته وفقاً للاستراتيجيات الموضوعة من قبل مجلس الادارة وبما يضمن تعظيم العوائد وتقليل المخاطر لذلك يجب ان يكون صاحب هذا المنصب من الكفاءات ذوي الخبرة الكبيرة في هذا المجال سواء أكان في الجانب الاداري او المللي او العملياتي ويفضل أن يدع هذا المدير بمجلس للخبراء يضم عدد من الخمتصين والمحتفين في هذا المجال من أجل تقديم المشورة له وكذلك ابداء الرأي لمجلس الادارة ورفع التقارير عن الاداء الصندوق والمدير التنفيذي وكذلك امكانية اقتراح النغيرات الملائمة في الاستراتيجية المتبعة تبعاً لتغير ظروف الاقتصاد العالمي والاقتصاد الداخلي . الاقسام الداخلية وهي الاقسام المسؤولة عن ادارة وتوجيه ومتابعة وتدقيق اتجاهات عمل الصندوق ومدى ملاثمهيا للاستراتيجية المقترحة في ضوء أهدافه وهذه الاقسام ترتبط مباشرة مع المدير التنفيذي وتعمل في ضوء توجيهاته وتقدم التقارير اليومية له حول مختلف القضايا التي تخص مجال عملها . م 


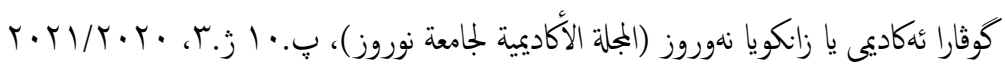

الاقسام والادارات المختلفة داخل الصندوق وعموماً فان التنويع يعد اساساً جيداً لإدارة مخاطر السوق والسيولة والمخاطر النظامية خاصة عندما يعتمد على معايير محايدة من ناحية الجغرافية أو القطاعية ،ويكن اعطاء بعض الحدية للوحدات الخختلفة في ادارة الخخاطر النسبية الخاصة بها من خلال تحفيزها على وضع اليات للسيطرة على المخاطر تعتمد على نظم معلومات دقيقة قادرة على وضع بموعة من المعايير التوجيهة مع ضمان الدقة والسرعة في التعامل مع المثغيرات الجديدة من خلال التوسع في التقارير المفسرة لكل نشاط مالي محلي أو دولي .

4. المبحث الثالث: محاكاة الاثر المستقلي لصندوق كوردستان السيادي على

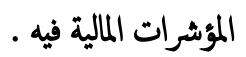

في هذا المبحث سوف نستخدم اسلوب المحاكاة العشوائية لتحليل مدى استجابة المؤشرات المالية الاساسية وخصوصآ صافي الثروة لوجود صندوق سيادي في اقليم كوردستان ، وذلك من خلال توضيح مدى تاثير نمو موجودات وعائدات

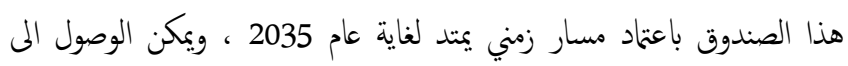
تحديد صافي الثروة في دولة ريعية مع وجود صندوق سيادي فها من خلال المعادلات الاتية (Ntamatungiro,2004,p15).

$W_{t+1}=A_{t+1}+F F G_{t+1}+V O_{t+1}$

$A_{t+1}=A_{t}(1+r)+F_{t+1}+Y O_{t+1}$

$F F G_{t+1}=F F G_{t}(1+\rho)+T O_{t+1}-Y O_{t+1}$

$$
V O_{t+1}=V O_{t}(1+r)-T O_{t}+(1+r) .
$$

الدين العام وهو أصغر من صفر .

YO

$$
\begin{aligned}
& \text { النفطي ( صندوق الاجيال FFG). } \\
& \text { م العائد على موارد FFG }
\end{aligned}
$$

ع V $\mathbf{V}$

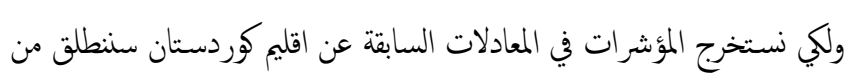
افتراضين اساسيين الوول يتثل بافتراض تخصيص 10\% من الايرادات النفطية السنوية لدع موجودات الصندوق السيادي ، والثاني هو افتراض تخصيص
عوائد تطابق معايير الدخل الثابت مع المحافظة على مستوى مقبول من الخاطرة .اما الوحدة الاخرى والتي يجب ان تكون موجودة ضمن فرع الاستثمار الخارجي هي وحدة الموجودات الحتقية وهي المسؤولة عن بناء محفظة متنوعة من الاصول العقارية والزراعية والصناعية والتي تهدف الى الاستفادة من فوائد تنويع الموجودات الحتيقية وخاصة العقارية وذلك من خلال ادارة فعالة تحقق عائد محسوب على المدى الطويل ولابد ان تكون لهذه الوحدة القدرة على تحديد وتسعير وادارة الخخاطر في الاصول الحتيقة والعمل على ادارة نهج تعاوني يتضمن مشاريع مشتركة مع شركاء دوليين من ذوي الخبرة .أما الوحدة الاخيرة في هذا الفرع فهي وحدة الاستثغارات البديلة وهي التي تهتم بالاستثار في الاموال السائلة غير التقليدية . أما في ما يتعلق بفرع الاستثمار الداخلي فانه هو الاخر يجب ان يظم مجموعة من الوحدات مثل وحدة الاسهم والتي تهتم بنداول الاسهم العائد للشركات المحلية سواء أكانت تابعة للقطاع الخاص أو العام وبذلك فان الصندوق هنا سوف يساهم في دع التمويل الداخلي لمثل هذه الشركات وكذا الحال بالنسبة لوحدة العقارات الداخلية التي يكن من خلال عملها التي تدع عمل هذا القطاع الحيوي في الاقتصاد وتساعد في اقامة العديد من المشاريع السكنية والسياحة التي تدع اقتصاد والاقليم، أما فيا يخص وحدة الدخل الثابت الداخلية فإنها بالثأكيد سوف تساهم في دع تمويل القطاعين العام والخاص من خلال الاستثمار في السندات وأذونات الخزينة الداخلية ،وبالانتقال المى وحدة البنى الارتكازية نلاحظ انها يككن ان تقدم مساعد كبيرة في اطار الاستثمار في البنى التحتية في الاقليم اذ تعمل هنا كستثمر مؤسسي يعمل وفق اليات السوق من خلال توجيه استثماراته نخو قطاعات مثل السكك الحديد والنقل البري والجوي والقطاع الصحي والقطاع التعليم والقطاعات الثقافية مثل الملاعب الرياضية والمراكز الثقافية ومن الافضل لمثل هذه الوحدة ان تقوم بإنشاء مركز أو معهد متخصص بالدراسات حول البنى الارتكازية يساعد في توضيح اهمية وعائد الاستثمار

ادارة الخخاطر تؤدي دوراً مركزياً في مثل هذه الصناديق والتي لابد هنا ان ترتبط بصورة مباثرة بالمدير التنفيذي للصندوق لما ينلككه من خبرة يساعده في هذا الجمال مجلس الخبراء المرتبط به فضلاً عن بموعة اللجان المشكلة عن 


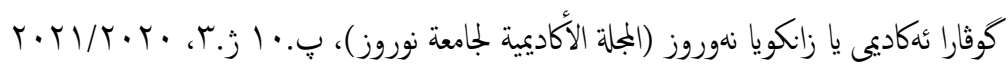

2015 نو (10.88 ترليون ID ) وهذا الرقّ يتوافق مع ماجاء في بيانات وزارة

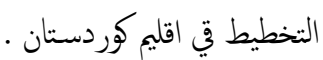
اما فيا يخص ايرادات النفط والتي تم افتراض انها ستعتمد على سعر للبرميل يقدر ب 60 \$ كمدل للسنوات القادمة ( وهو الحد الادنى كمعدل عام لغاية عام 2035 ) وبانتاج يفترض ان يتزايد بمعدل نخو 5\% سنويا لذلك يلاحظ ان المؤشر من المتوقع ان ينتقل من ادنى مستوى له كنسبة GDP غير النفطي (116. 13 \% ) في عام 2015 المى اعلى مستوى (170.61\%) وذلك في عام 2035 وعلى هذا الاساس ستاخذ ثروة النفط انجاها تصاعديا هي الاخرى خلال

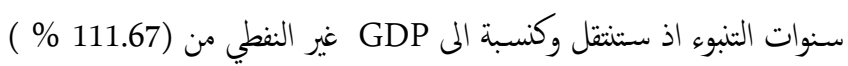
عام 2015 الى (164.05 \% ) عام 2035 وذلك على الرغز من ان GDP غير النفطي سوف يستمر بالمو بمعدل 3\% خلال المدة (2015 - 2035 ) ولكن نمو ثروة النفط والناشيء عن استقرار الفائدة عند 4\% سنويا ونمو الانتاج بمدل 5 سنويا سيدفع نحو زيادة النسبة . وبالانتقال الى الرصيد الاساسي الكلي نلاحظ انه من المتوقع ان يسجل يجزا متناقصا للمدة ( 2015 - 2022 ) ويبدا بعدها بتحقيق فائض على طول المدة المتبقية ومن الواضح هنا تاثير نمو ايرادات النفط ـ وعلى هذا الاساس سيحقق هذا الرصيد اعلى فائض في عام (2035 ) بنسبة (33.55\% من GDPغير النفطي ) . اما فيا يتعلق بالرصيد الاساسي غير النفطي فسوف نفترض ثباته عند نسبة جعز تقدر ب(120\% منGDP غير النفطي ) وهذه النسبة تم افتراضها بالاعتماد على معدل هذا العجز للسنوات ما بعد 2003 في اقليم كوردستان . وبالانتقال الى موجودات الصندوق السيادي والتي ستكون صفرا لغاية عام 2017 الذي تم افتراض ان الحكومة من الممكن ان تبدا فيه باعتاد هذا الصندوق وعلى افتراض انها سوف تخصص 10\% من ايرادات النفط لغرض دع موجوداته نلاحظ ان الموجودات ستصل المى اعلى مستوى لها عام 2035 اذ من المتوقع ان تسجل نسبة (216.5 \% من GDP غير النفطي ) والملاحظ في هذا المجال ان هذا المؤشر سيستمر بتحقيق نسب مرتفعه على الرغ من استمرار نمو GDP غير النفطي للاعوام المتنبا بها وذلك لان موجودات هذا الصندوق ستعتمد على ايرادات النفط التي من المفترض انها ستحقق نموا يقدر ب 5\% سنويا (نو

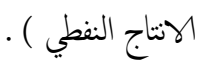

20\% من الايرادات النفطية السنوية لدعه، ـوسنعمد على بيانات عام 2015 فيم يتعلق ب GDP غير النفطي ، والايرادات ، والنفقات ، والعجز، والدين

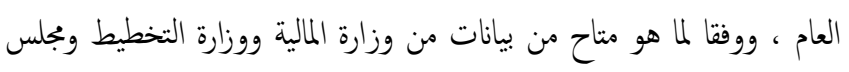

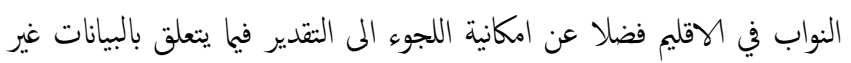
المتاحة وهذا التقدير يعتمد على اسس علمية مدروسة وعلى مقارنات مع ماهو مثاح من البيانات من حكومة المركز في العراق ـ اما فيا يخص نمو مؤشرات انتاج واسعار النفط فسوف يتم اعتمد اسعار عام 2015 والتي شهدت وخاصة في الربع الاخير منه تراجعا كيرا في مستوياتها ، وسوف يتم اعتماد الارقام المنشورة عن الانتاج النفطي في اقليم كوردستان مع اعطاء هامش لنمو الانتاج في ضوء الهمكانات المتاحة والبيانات المتوفرة عن الاحتياطات النفطية فيه اذ تح اختيار رق 45 مليار برميل كاحتياطات متوفرة في اقليم كوردستان مع امكانية استخراج في ضوء التكنلوجيا المتاحة تصل الى 55\% من الاحتياطات وتم تحديد هدف 1.5 مليون برميل يوميا كمد اقصى للانتاج المستهدف من اجل دف نفاذ النفط الى لى اكثر من 40 عامكا تم اقتراح معدل سعر للبرميل ب $\$ 60$ دولار للبرميل الواحد وعلى هذا الاساس تم افتراض ان الانتاح الحالي يقدر 750 الف برميل / يوم

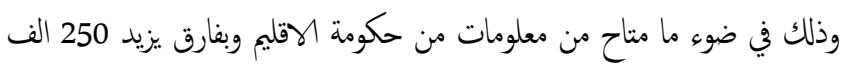
برميل عن مطالبات حكومة المركز (500 الف برميل /يوم ) لموازنة عام 2016 ، وتم ايظا افتزاض ان الانتاج سوف يمو بمعل ثابت يبلغ 5\% للسنوات العشرين القادمة (2015- 2035 ) ـ وفي ضوء المعطيات السابقة تمت المحاكة وفقا لما ياتي : 1.4 الافتراض الاول : اذا تم استقطاع 10\% من ايرادات النفط للصندوق

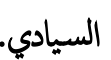
1.1.4 اثر وجود الصندوق السيادي على صافي الثوة في كوردستان من خلال الجدول رخ (3 ) نلاحظ ان GDP الغير نقطي قد انتقل من ادنى مستوى له عام 2015 اذ بلغ نحو (ID 10880 ) الى (ID 19650.4) عام 2035 وذلك تحت افتراض معدل نمو لهذا الناجت يبلغ 3\% سنويا ـ والجدير بالذكر ان هذا الناتج تم افتراضه على اساس العلاقة بين GDP الكلي ومساهمة الايرادات النفطية فيه والبالغة نحو 62 \% وهذ الرخ مؤشر لعموم العراق وفقا لمشاورات المادة 4 في العراق لعام 2013 ، 2014 ، ونظرا لكون GDP غير سنر النفطي لعموم العراق بشكل نخو 64 ترليون دينار عراقي وباخذ نسبة 17 \% مساهمة اقليم كوردستان في هذا الناتج يصبح GDP غير النفطي في الاقليم لعام 


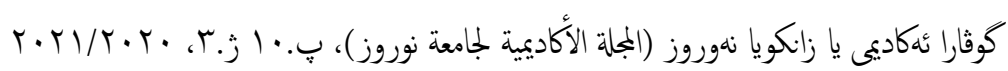

وهنا نلاحظ الفرق الشديد في صافي الثروة في الحالثين اذ ان وجود الصندوق السيادي يدع هذا المؤشر بشكل واضح وكير وهذا مايؤشر الثاثير الفعال له على لى الاستدامة المالية في اقليم وردستان .

والشكل رقٌ ( 5 ) يوضح مستوى واتجاه صافي الثروة بدون ومع وجود SWF في اقليم كوردستان والذي نلاحظ منه الثاثير الايجابي الواضح لوجود الصندوق

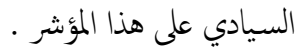

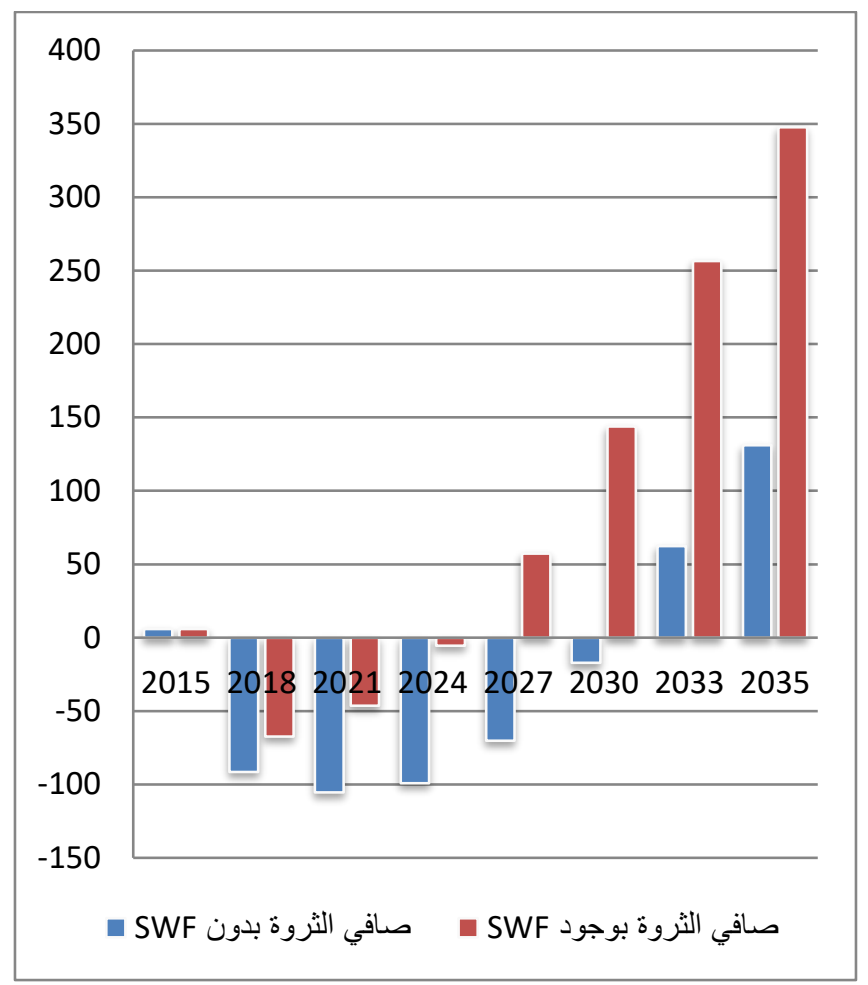

المصدر : من اعداد الباحث بالاعتاد على الجدول ( 3 )

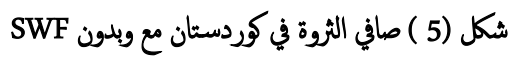

\subsection{4 اثر عائدات الصندوق السيادي على صافي الثروة في اقليم كودستان}

تناولنا في الفقرة السابقة اثرموجودات الصندوق السيادي على الثروة الصافية في اقليم كوردستان ، ولكن الرشادة الاقتصادية تفرض ضرورة توظيفها باتجاهات تدر عائد مقبول وعدم ابقائها معطلة لذلك سنحاول في هذا المجال افتراض عائد مككن ان يجقةه الصندوق السيادي المقتح من خلال توظيف موجوداته داخليا وخارجيا والجدول رقز (4 ) يوضح اثر ثلاثة عائدات افتراضية على صافي الثزوة

$$
\text { والذي نلاحظ من خلاله ما ياتي : }
$$

عند افتراض عائد الصندوق 2\% نلاحظ ان موجودات الصندوق السيادي كنسبة الى GDP الغير نفطي انتقلت من (215.6\% ) في حالة عدم وجود عائد الى (220.83 \% ) في حالة وجود عائد (2\% ) وكذا

\section{جدول ( 3 ) تحليل الاثر المستقبلي الصندوق السيادي على الثوة الصافية للكومة} كوردستان للمدة 2015-2035 ( نسبة الى GDP غير النطي ما عدا ما يشار اليه )

\begin{tabular}{|c|c|c|c|c|c|c|c|c|}
\hline 2035 & 2033 & 2030 & 2027 & 2024 & 2021 & 2018 & 2015 & \\
\hline 19650.4 & 18522.4 & 16950.6 & 15512.2 & 14195.9 & 12991.2 & 11888.8 & 10880 & النفطي (مليار تيار $\quad$ GDP \\
\hline 32.93 & 95.54 & 166.22 & 210.97 & 231.87 & 230.87 & 209.78 & 105.69 & الدين العام \\
\hline-120 & -120 & -120 & -120 & -120 & -120 & -120 & -137.27 & النفطي الاساسي غير \\
\hline 170.61 & 164.17 & 154.97 & 146.28 & 138.08 & 130.34 & 123.03 & 116.13 & ايرادات النفط \\
\hline 153.55 & 147.76 & 139.47 & 131.65 & 124.27 & 117.31 & 110.73 & 116.13 & الميرادات المخصص لموازنة من \\
\hline 17.06 & 16.41 & 15.49 & 14.62 & 13.80 & 13.03 & 12.30 & 0 & المسيادي \\
\hline 33.55 & 27.76 & 19.47 & 11.65 & 4.27 & -2.68 & -9.26 & -21.13 & الكلي $\quad$ الرصيد \\
\hline 4 & 4 & 4 & 4 & 4 & 4 & 4 & 4 & الاسمي (نسبة) \\
\hline 3 & 3 & 3 & 3 & 3 & 3 & 3 & 3 & 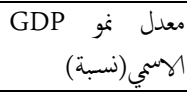 \\
\hline 60 & 60 & 60 & 60 & 60 & 60 & 60 & 60 & 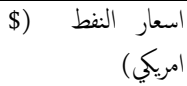 \\
\hline 5 & 5 & 5 & 5 & 5 & 5 & 5 & 5 & تغيرات انتاج النفط \\
\hline 164.05 & 157.86 & 149.01 & 140.66 & 132.77 & 125.33 & 118.30 & 111.67 & ثروة النفط \\
\hline 216.50 & 194.35 & 161.07 & 127.58 & 93.71 & 59.25 & 24.02 & 0 & السيادي \\
\hline 131.12 & 62.31 & -17.21 & -70.311 & -99.10 & -105.541 & -91.48 & 5.97 & $\begin{array}{r}\text { صافي الثروة (بدون } \\
\text { (SWF }\end{array}$ \\
\hline 347.63 & 256.66 & 143.85 & 57.26 & -5.39 & -46.28 & -67.45 & 5.97 & $\begin{array}{r}\text { صافي الثروة (بوجود } \\
\text { (SWF }\end{array}$ \\
\hline
\end{tabular}

المصدر : من اعداد الباحث بالاعتماد على :

1- حكومة اقليم كوردستان ، وزارة المالية ، دائرة الموازنة ، الموازنات لسنوات مختلفة .

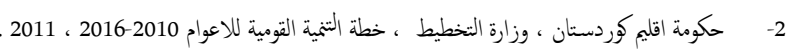
3- مجلس النواب في اقليم كوردستان ، اللجنة المالية ، بيانات غير منشورة . 4- وزارة النفط والموارد في اقليم كوردستان ، الاحصاءات . 5- م المعادلات 1 ، 2، 3، 4 2الانفة الذكر . اما فيا يتعلق بالمؤشرين الاهم في الجدول رقّ (3 ) وها صافي الثروة بدون الصندوق السيادي ، وصافي الثروة مع الصندوق السيادي نلاحظ ان الاول اخذ اتجاها سالبا منذ عام 2016 وهذا الموضوع متوقع في ظل التزاجع الشديد الذي تشهده اسعار النفط هذا العام ، ولكن هذا المؤشر من المتوقع ان يبدا بالتزايد اعتبارا من عام (2022 ) حتى يصل الى اعلى مستوى متوقع خلال المدة المتنبا بها (131.32 \% كنسبة الى GDP غير النفطي) وذلك عام (2035 ) . وبالانتقال المى المؤشر الثاني (صاني الثروة عع وجود الصندوق السيادي ) نلاحظ انه من المتوقع ان يشهد اتجاها تصاعديا منذ عام (2019 ) وذلك تحت تاثير وجود الصندوق السيادي حتى يسجل المؤشر نسبة (347.63 \%) وذلك عام 2035، 


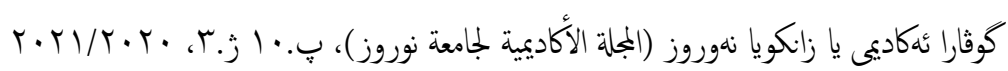

2.4 الافتراض الثاني : استقطاع 20\% من ايرادات النفط للصندوق السيادي . هذا الافتراض يقوم على اساس ان الحكومة سوف تتخذ قرارا بتوجيه (20\% ) من ايرادات النفط نحو تنمية ودو موجودات الصندوق السيادي في هذه الحالة فان الثاثيرات ستكون متباينه خاصة مع افتراض ثبات اسعار النفط عند مستوى نو \$60/ برميل ، وافتراض نمو الانتاج بمعل لايتجاوز 5\% سنويا ، وكذلك سك سلك استمرار نمو GDP غير النفطي بمعدل 3\% سنويا ، والجدول رقٌ (5 ) يوضح النتائج المتتبة على هذا الافتراض وكما ياتي : ماتئ جدول ( 5 ) تحليل الاثر المستقبلي الصندوق السيادي على الثرة الصافية لمكومة كردستان للمدة 2015-2035 ( نسبة الم GDP غير النفطي ما عدا ما يشار اليه )

\begin{tabular}{|c|c|c|c|c|c|c|c|c|}
\hline 2035 & 2033 & 2030 & 2027 & 2024 & 2021 & 2018 & 2015 & \\
\hline 19650.4 & 18522.4 & 16950.6 & 15512.2 & 14195.9 & 12991.2 & 11888.8 & 10880 & $\begin{array}{r}\text { GDP } \\
\text { (ID }\end{array}$ \\
\hline 330.767 & 354.36 & 370.26 & 364.44 & 338.73 & 294.81 & 234.27 & 105.69 & الدين العام \\
\hline-120 & -120 & -120 & -120 & -120 & -120 & -120 & $\begin{array}{l}- \\
137.27\end{array}$ & النفطيد الوساسي غير \\
\hline 170.61 & 164.17 & 154.97 & 146.28 & 138.08 & 130.34 & 123.03 & 116.13 & ايرادات النفط \\
\hline 136.49 & 131.34 & 123.98 & 117.02 & 110.46 & 104.27 & 98.42 & 116.13 & الخيرادات الموازنة من \\
\hline 34.12 & 32.83 & 30.99 & 29.25 & 27.61 & 26.06 & 24.60 & 0 & الغيادي $\quad$ اللصندوق \\
\hline 16.49 & 11.34 & 3.98 & -2.97 & -9.53 & -15.72 & -21.57 & -21.13 & الرصيد الكساسي الكلي \\
\hline 4 & 4 & 4 & 4 & 4 & 4 & 4 & 4 & معدل \\
\hline 3 & 3 & 3 & 3 & 3 & 3 & 3 & 3 & GDP معدل تونسة) \\
\hline 60 & 60 & 60 & 60 & 60 & 60 & 60 & 60 & اسعار النطظ (\$ امريكي) \\
\hline 5 & 5 & 5 & 5 & 5 & 5 & 5 & 5 & تغغرات انتاج النفط (نسبة) \\
\hline 164.05 & 157.86 & 149.01 & 140.66 & 132.77 & 125.33 & 118.30 & 111.67 & ثزوة النفط \\
\hline 433.01 & 388.70 & 322.14 & 255.17 & 187.42 & 118.50 & 48.04 & & السوجيادي \\
\hline-166.70 & -196.50 & -221.24 & -223.78 & -205.95 & -169.48 & -115.97 & 5.97 & صافي الثروة (يدون SWF) \\
\hline 266.30 & 192.19 & 100.90 & 31.38 & -18.53 & -50.97 & -67.92 & 5.97 & 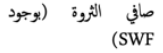 \\
\hline
\end{tabular}

فيا يتعلق فيا يتعلق بمؤشرات الخخص الموازنه والخخصص للصندوق السيادي نلاحظ ان الوول شهد تزاجعا كنسبة الGDPغير النفطي عن ماهو موجود في الافتزاض الاول اما الخحص للصندوق فشهد تزايد في نسبته وهذه حالة منطقية في ضوء الافتراض الثاني ، ولكن من المتوقع ان

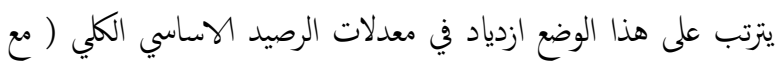
افتراض ثبات الرصيد الاساسي غير النفطي عند 120 - \% ) وكذلك معدلات الدين العام كنسبة الى GDP وهذا واضح من خلال المقارنة بين المؤشرين في جدول ( 3) والجدول (4 ) فيا يخص شروة النفط سوف تبقى دون تنيير وذلك لانها لاتربط بالافتراضين لانها حاصل خصم الايرادات الكلية للنفط . بالانتقال الى المؤشر الاهم في هذا المجال والمعبر عن الاستدامة المالية وهو صافي الثروة كنسبة الى GDP غير النفطي نلاحظ انه شهد تراجعا عن
الحال بالنسبة لمؤشر صافي الثروة الذي انتقل من (347.6\% - )لالى (351.96) وهذا يؤشر حقيقة ان وجود العائد اثر ايجابا على صافي الثروة . عند افتراض عائد للصندوق (5\%) نلاحظ ان موجودات الصندوق وصافي الثروة كنسبة الى GDP غير النمطي انتقلت من (215.6 ) (347.6 \%) على التوالي الى (227.3\% ) و (358.45\% ) على التوالي عند افتراض عائد للصندوق (8\%) نلاحظ ان كلا من موجودات SWF وصافي الثروة انتقل من (215.6\% )و (347.6 \% ) على التوالي الى (233.82 \% و (364.95 \% ) على التوالي وهذا يؤشر مقدار الزيادة الكبيرة في صافي الثروة تحت ثاثير نمو عائدات الصندوق السيادي وهكذا كلما استطاع هذا الصندوق ان يحقق عائد اكبر فان اثره سوف يكون ايجابيا على صافي الثروة في الاقليم . جدول 4. تحليل اثر تغير عائد الصندوق السيادي على الثروة الصافية لمكومة كرردستان اللمدة 2015-2035 ( نسبة الم GDP غير النفطي ما عدا ما يشار اليه )

\begin{tabular}{|c|c|c|c|c|c|c|c|c|}
\hline & 2033 & 2030 & 2027 & 2024 & 2021 & 2018 & 2015 & \\
\hline & & & & & & \multicolumn{3}{|c|}{ بنما عاثد الصندو السياني 2\% } \\
\hline 32.93 & 95.54 & 166.22 & 210.97 & 231.87 & 230.87 & 209.78 & 105.69 & 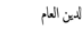 \\
\hline 164.05 & 157.86 & 149.01 & 140.66 & 132.77 & ${ }^{125.33}$ & 118.30 & 111.67 & 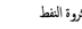 \\
\hline 315.40 & 272.13 & 212.53 & 158.63 & 109.79 & 65.42 & 24.99 & 0 & SWF كوجودات SWF \\
\hline \multirow[t]{2}{*}{446.53} & 334.45 & 195.31 & 88.32 & 10.69 & -40.12 & .66 .48 & 5.97 & 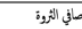 \\
\hline & & & & & & \multicolumn{3}{|c|}{ مندما عاثد الصندر السيادي 5\% } \\
\hline 32.93 & 95.54 & 166.22 & 210.97 & 231.87 & 230.87 & 209.78 & 105.69 & 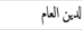 \\
\hline 164.05 & 157.86 & 149.01 & 140.66 & 132.77 & 125.33 & 118.30 & 111.67 & 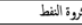 \\
\hline 547.09 & 445.45 & 318.91 & 218.21 & 138.45 & 75.62 & 26.48 & 0 & SWF كوبودات SWF \\
\hline \multirow[t]{2}{*}{678.224} & 507.7727562 & 301.7016707 & 147.9004413 & 39.35032812 & -29.91717096 & -64.99763117 & 5.97 & 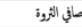 \\
\hline & & & & & & \multicolumn{3}{|c|}{ عندا عاثد الصندق السياني 8\% } \\
\hline 32.93 & 95.54 & 166.22 & 210.97 & 231.87 & 230.87 & 209.78 & 105.69 & المالمين الهام \\
\hline 164.05 & 157.86 & 149.01 & 140.66 & 132.77 & ${ }^{125.33}$ & ${ }^{118.30}$ & 111.67 & 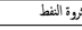 \\
\hline 934.37 & 79.10 & 473.10 & 297.48 & 173.45 & 87.06 & 28.01 & 0 & SWF بوجودات SWF \\
\hline 1065.49 & 781.41 & 455.89 & 227.17 & 74.34 & -18.47 & -63.46 & 5.97 & 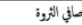 \\
\hline
\end{tabular}

المصدر : من اعداد الباحث بالاعتماد على جدول ( 3 ) . والشكل رق (6) يوضح صافي الثروة في كوردستان عند مستويات العائد الثلاثة (\%8،\%5،\%2)

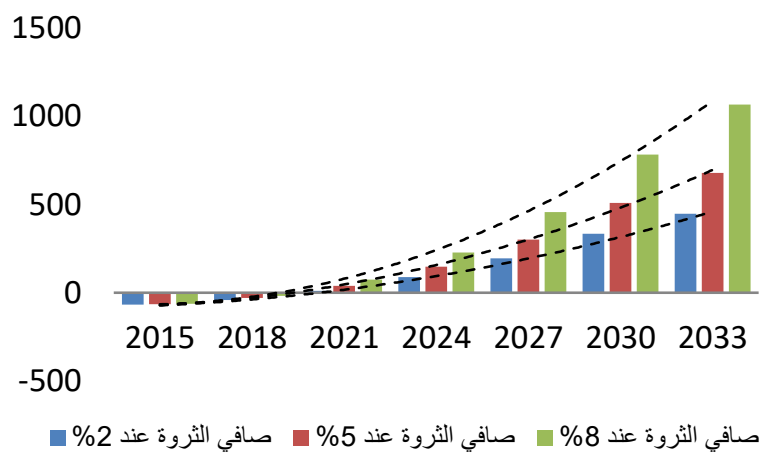

1000

500

0 2015201820212024202720302033 $-500$

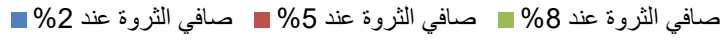

المصدر من اعداد الباحث بالاعتاد على الجدول ( 4 ) . شكل (6) صافي ثروة حكومة كردستان عند مستويات مختلفة من العائد على كWF

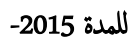




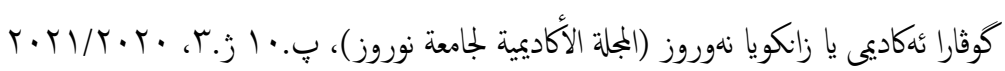

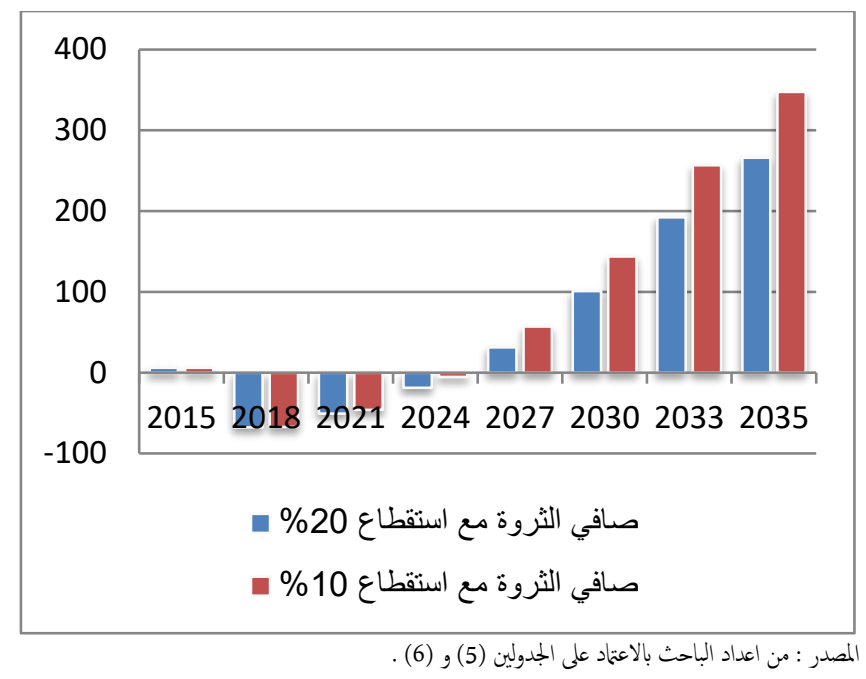

شكل (7) صافي ثروة الحكومة مع استقطاع 10\% او 20\% من ايرادات النط

SWF الم

والجدير بالذكر هنا ان صافي الثروة من المتوقع ان يصبح في حالة افضل اذا ما تح افتراض ان الصندوق السيادي المقترح بناءه من خلال استقطاع 20\% من ايرادات النفط سوف يجقق عائد على موجوداته يفوق 2\% سنويا عندها فقط سيكون من مصلحة حكومة الاقليم ومن الجدي اقتصاديا اللجوء الى خيار استقطاع 20\% بدلا من 10\% من الايرادات النفطية السنوية والشكل رخ (8) ) يوضح تغيرات صافي الثروة لحكومة اقليم كوردستان مع افتراض ثلاثة عوائد سنوية مختلفة على موجودات الصندوق السيادي المقتح ، ومن الواضح في الشكل ان العوائد الثلاثة تؤمن مسارا تصاعديا لهذا المؤشر المهم والمعبر عن

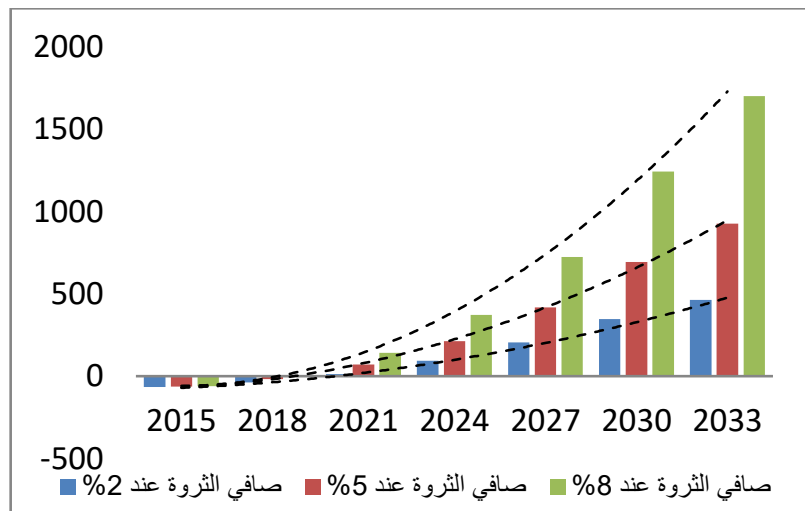

المصدر : من اعداد الباحثة بالاعتاد على جدول (6)

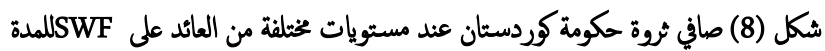
2035-2015
ماهو موجود في الافتراض الاول جدول (4 ) اذ ان صافي الثروة في عام 2035 بلغ في الافتراض الاول (347.63\%) بينا لم يسجل في الافتراض الثاني سوى (266.3\%) وهذا يؤشر حقيقة كمة هوان زيادة ما مخصص اللصندوق السيادي من ايرادات النفط عمل على رفع معدلات العجز ( او خفض الرصيد الاساسي الكلي ) وهذا مادفع الى مزيد من الديون والى لى ارتفاع نسبة الدين الى GDP، هذا الارتفاع ساهم في خفض نسبة صافي الثروة على الرغز من زيادة موجودات الصندوق السيادي مع اقتطاع 20\% من الايرادات النفطية لدعها وهذا الموضوع يفسر حقيقة همة تؤشر ان الدولة لها طاقة استيعابية لتحمل الدين وان هناك حدودا له اذا تم تجاوزها يصبح هذا الدين متفجرا في خط سيره وهذا مايوثر سلبا على صافي الثروة ومن ثم الاستدامة المالية هذا من جانب ومن جانب اخر فان توظيف موجودات الصندوق السيادي والعائدات المتحقق عليه قد لاتغطي مقدار العجز والدين الا بشكل محدود وهذا ما نلاحظه في الجدول رقٌ (6) رئ الذي يوضح اثر عائدات الصندوق السيادي على صافي الثروة في حالة افتراض ثلاثة عوائد مختلفة (2\% ، 5\% ، 8\% ) .

\section{جدول 6. تحليل اثر تغير عائد الصندوق السيادي على الثرة الصافية لمكومة} كوردستان للمدة 2015-2035 ( نسبة الى GDP غير النطي ما عدا ما يشار اليه )

\begin{tabular}{|c|c|c|c|c|c|c|c|c|c|}
\hline 203 & & 2033 & 2030 & 2027 & 2024 & 2021 & 2018 & 2015 & \\
\hline & & & & & & & \multicolumn{3}{|c|}{ عندما عائد الصندو السيادي 2\% } \\
\hline 330.767 & 354.36 & & 370.26 & 364.44 & 338.73 & 294.81 & 234.27 & 105.69 & المين العام \\
\hline 164.05 & 157.86 & & 149.01 & 140.66 & 132.77 & 125.33 & 118.30 & 111.67 & ثروة الثط \\
\hline 630.81 & 544.27 & & 425.06 & 317.27 & 219.59 & 130.84 & 49.98 & 0 & $\begin{array}{c}\text { مWF } \\
\text { SWF }\end{array}$ \\
\hline \multirow[t]{2}{*}{464.11} & 347.77 & & 203.82 & 93.49 & 13.63 & -38.64 & -65.98 & 5.97 & 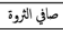 \\
\hline & & & & & & & \multicolumn{3}{|c|}{ عثلما عائد الصندق السيادي 5\% } \\
\hline 330.767 & 354.36 & & 370.26 & 364.44 & 338.73 & 294.81 & 234.27 & 105.69 & المين العام \\
\hline 164.05 & 157.86 & & 149.01 & 140.66 & 132.77 & 125.33 & 118.30 & 111.67 & 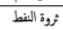 \\
\hline 1094.19 & 890.91 & & 637.83 & 436.43 & 276.90 & 151.24 & 52.96 & 0 & $\begin{array}{c}\text { مWF } \\
\text { SWF }\end{array}$ \\
\hline \multirow[t]{2}{*}{927.49} & 694.41 & & 416.58 & 212.65 & 70.94 & -18.23 & 63.0 & 5.97 & صافي الثروة \\
\hline & & & & & & & \multicolumn{3}{|c|}{ عثلما عائد الصندو السيادي 86 } \\
\hline 330.767 & 354.36 & & 370.26 & 364.44 & 338.73 & 294.81 & 234.27 & 105.69 & المين العام \\
\hline 164.05 & 157.86 & & 149.01 & 140.66 & 132.77 & 125.33 & 118.30 & 111.67 & زئزة الثط \\
\hline 1868.7 & 1438.2 & & 946.21 & 594.97 & 346.90 & 174.12 & 56.03 & 0 & $\begin{array}{l}\text { موجوات } \\
\text { SWFF }\end{array}$ \\
\hline 1702.0 & 1241.7 & & 724.96 & 371.19 & 140.94 & 4.64 & -59.93 & 5.97 & 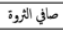 \\
\hline
\end{tabular}

اذ انه حتى في حالة عائد 8\% فان نسبة صافي الثروة الى GDP لن تتجاوز الكثر (5 ) الثر من (300\% ) وهو اقل من صافي الثروة المسجل في عام 2035 في جدول (5) والمتمد على استقطاعات (10\%) من ايراردات الصندوق السيادي ، والشكل رقة (7 ) يوضح صافي الثروة المتوقع في اقليم كوردستان للمدة 2015 - 2035 في حالة استقطاع 10 \% و20 \% من ايرادات النفط لدع الصندوق السيادي ، اذ نلاحظ منه ان صافي الثزوة يكون في حال افضل مع 10\% استقطاع للصندوق

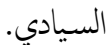




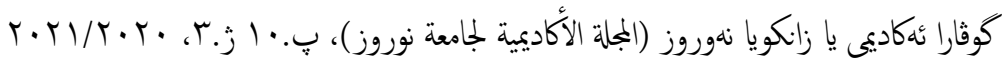

(2035-2015) وذلك مع عدم اعتاد أي عائد على موجودات الصندوق

ولكن بجرد اقتزاح عائد (2\%) عليها فان صافي الثروة سياخذ مساراً

1.5 الوستناجات

تصاعدياً ويصبح الحال أفضل مع اعتماد عائد 5\% او 8\% وهذه النتيجة تؤشر حقيقة ان وجود صندوق مع عائد لا يقل عن (2\%) يربح فرضية استقطاع (20\%) من ايرادات النفط للصندوق على الافتراض الاول

ان بناء صندوق سيادي معتمد على ايرادات المورد الناضب (النفط ) في اقليم كوردستان يككن ان يسام بشكل كير في دع الاستدامة المالية فيه وضان الرفاهية الاقتصادية للأجيال الحالية والقادمة وان مدى نجاح الموضوع يعتمد بشكل كير على طريقة ادارة هذا الصندوق والقدرة على لى الاستغلال الامثل لموارده المناحة من خلال التوظيف الفعال داخلياً أو

في اقليم كوردستان ومن اجل موابهة معضلة الاستعداد لعصر ما بعد نضوب النفط سواء اكان هذا النضوب طبيعيا او فنيا بسبب تطور المصادر البديلة من الضروري العمل على بناء صندوق سيادي وذلك من خلال

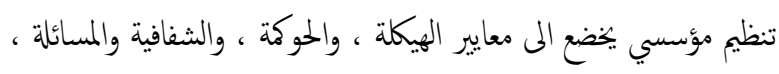
والسلوك الواضح المتعلقة بالصناديق السيادية من اجل اطلاع الملاك الاساسيين للثروة وهم مواطني الاقليم على كافة التفاصيل المتعلقة بالموارد والارباح والاستثار والامور الاخرى مع تزويده بجهاز من الموظفين ذوي الكفاءة والخبرة العالية في اختصاصات عمل الصندوق وكذلك اعطائه مرونة في مجال مصادر التمويل وذلك من خلال ربطه بصناديق استثارية أو

هناك طاقة استيعابية كبيرة للاستثمار في الاقليم وقطاعات كاملة مكن أن تحقق فائض يعتد به واموال الصندوق السيادي يمكن وفق الرؤية التي اعتمدها البحث أن تساهم في تفطية هذه الاستثمارات وبذلك يمكن تجنب مخاطر الاستثار الخارجي من جهة والتعويض عن النقص الذي قديحصل في الانفاق الحكوي بسبب تحويل جزء من ايرادات النفط الى الصندوق السيادي وهذا الموضوع لابد أن يعزز بمزيد من الدراسات التي تتييم وضع القطاعات وتحدد الامثلية في توجيه الاستثارات وتوظيف الاموال .

\section{ان التناي المستمر في الانفاق الحكوي وما يتزتب عليه من عجز في الموازنة يكثل عائق اساسي أمام الاستدامة المالية وقد تفامٍ هذا الامر في اقليم كوردستان بشكل خطير في السنوات الاخيرة خاصة مع افتقار الحكومة للكثير من الادوات المالية التي يككن ان تساعد في هذا المجال .}

لازال النفط يشكل الركيزة الاساسية للإيرادات العامة في الاقليم وهو يشكل اكثر من (90\%) منها الامر الذي يعني احادية الجانب في الاقتصاد وريعيته القائمة على مورد واحد ناضب هو النفط والذي هو الاخر عرضة للتقلبات في اسعاره وانتاجه الذي لازال مقتصرا على كونه مادة اولية تصدر الى الخارج من دون ان يتحول الى قاعدة صناعية نفطية بترويمياوية تساعد

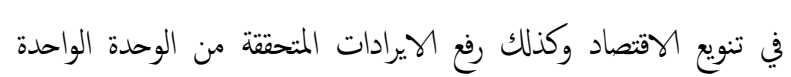

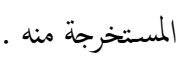
من خلال تجارب الدول الريعية النفطية في الصناديق السيادية فان الاقليم يككن وفي ضوء الممكنات المتاحة حالياً البدء ببناء صندوق سيادي معتمد على الموارد النفية خاصة مع التوقعات التي تشير الى ان اسعار النفط

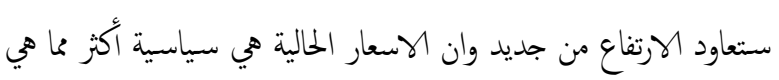
اقتصادية. في ضوء المعطيات والتوقعات التي ناقشها البحث فان الحكومة تستطيع استقطاع فقط (10\%)من الايرادات النفطية لغرض دئ موجودات الصندوق المقترح وذلك لان المبالغة في هذا الامر من الممكن ان توقع

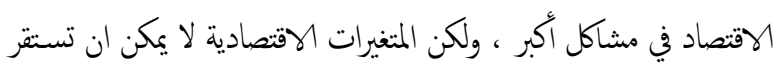
على مستوى واحد المى الابد وان التغير الايجابي للمتغيرات مثل الرصيد الاساسي الغير النفطي والرصيد الاساسي الكلي ومن ثم الدين العام مكنن ان تساهم في دع فكرة زيادة النسبة المخصصة من الايرادات النفطية للصندوق السيادي على الرغز من ان المتغيرات السابقة تتأثر بالإيرادات النفية التي ترتبط بالاجل القصير بإنتاج النفط وأسعاره وفي الاجلين المتوسط والطويل بالقدرة على الاستغلال الامثل للوحدة المنتجة منه . عند اقتزاح استقطاع (20\%) من الايرادات النفطية في اقليم كوردستان الى الصندوق السيادي فان النتيجة كانت هي تراجع صافي الثروة للمدة 
6. الدوسكي، ازاد أحمد سعدون ، التجربة الاقتصادية لاقليم كوردستان

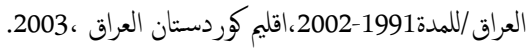

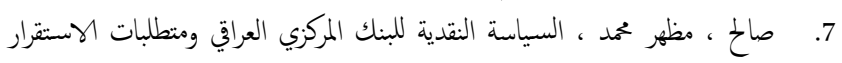

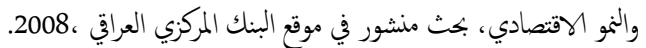

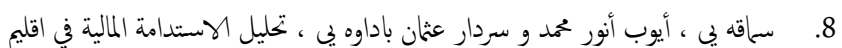

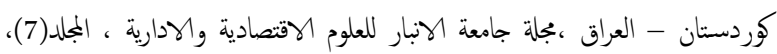
العدد (13)، 2015.

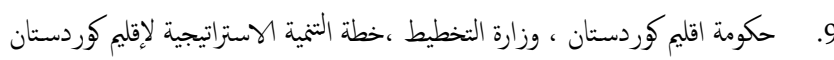

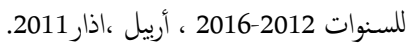

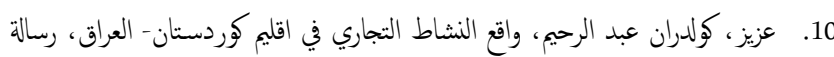

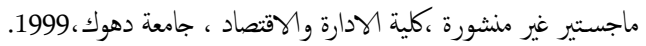

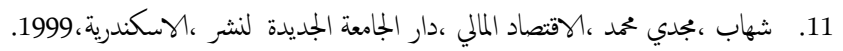

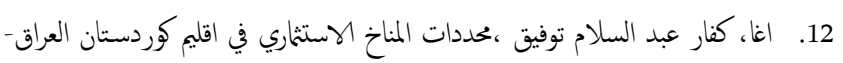

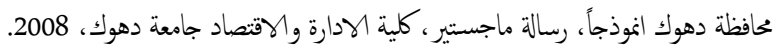

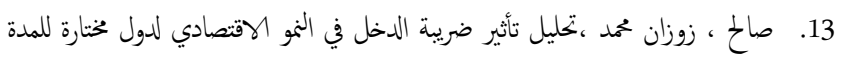

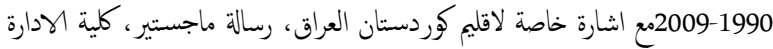

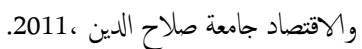
14. الحيدري، هيوا عثمان اسماعيل ،خلحليل أثر تقلبات سعر الصرف الاجنبي في الموازنة

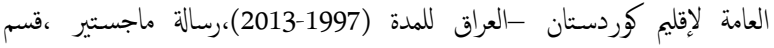

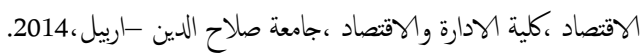

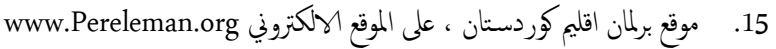

16. Jain, S. Integrating Hedge fund strategies in sovereign wealth portfolios, Citi capital advisors, P: 3, 2009

17. Ntamatungiro, J. Fiscal sustainability in heavily indebted countries dependent nonrenewable resources: The case of Gabon, IMF working paper, WP/04/30, February 2004
في اقليم كوردستان من الضروي العمل على ايجاد فصل بين الموازنة العامة للحكومة وموازنة المورد الناضب وبما يكفل تجنب الموازنات التكيلية ورفع معدلات الادخار وذلك من اجل عدم الانغهاس بالمرض الهولندي وهيمنة الايرادات النفطية من جهة وتامين موارد اكثر للصندوق السيادي المتترح الامر الذي يعطيه مرونة اكبر في تبني الستراتيجية المحفظية المثلى والمعبر عنها بتعظيم العائد وتقليل الخخاطرة . من اجل توفير مبررات النجاح للصندوف المقترح في كوردستان وخاصة مايتعلق ببنيته يقتزح البحث ان تقوم الحكومة مبدئيا بتخصيص مبلغ لايقل عن مليار دولار كاس مال اولي ومن ثم وضع قانون يضمن تحويل 10\% من ايرادات النفط والغاز للسنوات الخمسة القادمة وهي فترة انتقالية تحتابها الحكومة حتى يتسنى لها الفصل بين الموازنة العامة وموازنة المورد الناضب ومن ثم تقوم لاحقا بتحويل كل ايرادات المورد الناضب الى هذا الصندوق مع وضع تشريع يضمن السحب منه لدع الموازنة ضمن حدود لاتتجاوز العائدات السنوية التي يحققها مع فيا يتعلق باستثمرات الصندوق يقترح البحث مبدئيا ان يتم توجيه 70\% منها للاستثار في القطاع النفي وقطاع السياحة داخل الاقليم وبذلك نضمن الهدف التنموي للصندوق والذي سوف يمارسه لاهم قطاعين مؤهلين لتحقيق فائض قيمة اعلى من غرها وفي مدة قصيرة ، اما ال30\% الباقية فيتم توجيها نحو محفظة عائد نضمن من خلالها الحفاظ على قيمة الموجودات اولا ومن ثم بناء سمعة للصندوق وامكانية للحصول على تصنيفات مثقدمة في الجمال المالي العالمي مع ضمان الحصول على التجربة والخبرة لادارة الصندوق في هذا الاطار - مال

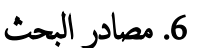

1. 2. ، القاهرة،1988.

3. مصطفى ،أحد فريد و سهير محد السيد ،الاقتصاد المالي بين النظرية والتطبيق

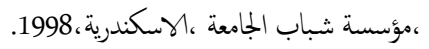
4. العبيدي، سعيد علي ، اقتصاديات المالية العامة ،دار دجلة لنشر والتوزيع ،عان، النعان، .2011 5. الدوسكي ، ازاد أحمد سعدون، واقع قطاع النفط في اقليم كوردستان العراق، مجلة جامعة نوروز - العدد الاول-2013 الموسن إندون 